九州大学学術情報リポジトリ

Kyushu University Institutional Repository

\title{
Generation of biohybrid implants using a multipotent human periodontal ligament cell line and bioactive core materials
}

Ono, Taiga

Department of Endodontology and Operative Dentistry, Faculty of Dental Science, Kyushu University

Tomokiyo, Atsushi

Department of Endodontology, Kyushu University Hospital

Ipposhi, Keita

Department of Endodontology and Operative Dentistry, Faculty of Dental Science, Kyushu University

Yamashita, Kozue

Department of Endodontology and Operative Dentistry, Faculty of Dental Science, Kyushu University

他

http://hdl. handle. net/2324/4377813

出版情報: Journal of Cellular Physiology, pp.1-12, 2021-02-19. Wily バージョン：

権利関係 : 
Generation of biohybrid implants using a multipotent human periodontal ligament cell line and bioactive core materials

Running title: Biohybrid implant from PDL cell line and HA core

Taiga Ono ${ }^{1,2}$, Atsushi Tomokiyo ${ }^{2}$, Keita Ipposhi $^{1}$, Kozue Yamashita $^{1}$, M. Anas

Alhasan $^{1}$, Yudai Miyazaki ${ }^{3}$, Yoshihiro Kunitomi ${ }^{3}$, Akira Tsuchiya ${ }^{4}$, Kunio Ishikawa $^{4}$, Hidefumi Maeda ${ }^{1,2}$

${ }^{1}$ Department of Endodontology and Operative Dentistry, Faculty of Dental Science, Kyushu University. ${ }^{2}$ Department of Endodontology, Kyushu University Hospital. ${ }^{3}$ Cyfuse Biomedical K.K. ${ }^{4}$ Department of Biomaterials, Faculty of Dental Science, Kyushu University.

*The corresponding author for this manuscript is Atsushi Tomokiyo, D.D.S., Ph.D. Atsushi Tomokiyo, D.D.S., Ph.D.

Department of Endodontology, Kyushu University Hospital, Higashi-ku, Fukuoka-shi, Fukuoka, Japan.

Telephone: +81926436432 Facsimile: +81926436366

E-mail:tomokiyo@dent.kyushu-u.ac.jp 


\begin{abstract}
We aimed to generate periodontal ligament (PDL) tissue-like structures from a multipotent human PDL cell line using 3D bioprinting technology and to incorporate these structures with bioactive core materials to develop a new biohybrid implant system. After 3D bioprinting, single cell spheroids were able to form 3D tubular structures (3DTBs). We established three types of complexes using 3DTBs and different core materials: 3DTB-titanium core (TIC), 3DTB-hydroxyapatite core (HAC), and 3DTB without a core material (WOC). The expressions of PDL-, angiogenesis-, cementum-, and bone-related genes were significantly increased in the three complexes compared with monolayer-cultured cells. Abundant collagen fibers and cells positive for the above markers were confirmed in the three complexes. However, more positive cells were detected in HAC than in WOC or TIC. The present results suggest that 3Dbioprinted structures and hydroxyapatite core materials can function similarly to the PDL and may be useful for the development of a new biohybrid implant system.
\end{abstract}

Keywords: Periodontal Ligament, Three-Dimensional Printing, Pathology, Histology, Growth and Development 


\section{Introduction}

Historically, dentures and bridges were the accepted treatment for missing teeth. Dental implants have emerged as a new prosthetic treatment option and perform a crucial role in oral rehabilitation. Consequently, dental implants are successful in increasing patients' satisfaction in relation to chewing efficiency, physical health, and esthetics. The typical implant consists of three parts: the body, the abutment, and the crown. The implant body is mainly composed of a bioinert material such as titanium and works in vivo by a direct structural and functional connection between the ordered alveolar bone and the surface of the load in a process known as osseointegration (Brånemark et al., 1977). Clinically, osseointegration provides mechanical anchorage of the implant body that persists under normal conditions of oral function. Many previous studies have made changes to the shape and surface characteristics of the implant body to promote osseointegration. However, unlike natural teeth, the implant body is not surrounded by a periodontal ligament (PDL). The PDL is a highly specialized connective tissue that firmly connects natural teeth with the peripheral alveolar bone (Carnes, Maeder, \& Graves, 1997). The PDL is also involved in the nutrition, repair, sensory capacity, and immune defense of the teeth (Shimono et al., 2003). Therefore, homeostasis, sensory transmission, and host defense mechanisms against infection are impaired around the osseointegrated implant body. Several recent studies have reported the development of a new biohybrid implant system that provides PDL cells for the implant body to simulate a natural tooth (Lee et al., 2017; Lin et al., 2011; Washio et al., 2018). Many such studies have used the cell sheet technique to generate a true biological attachment between PDL cells and the implant body. This technique preserves cell-to-cell interactions, thereby enabling a high concentration of cells and uniform cell distribution, and thus promoting tissue regeneration (Takeuchi et al., 2016). However, the formation of multilayered cell sheets is difficult, and the PDL contains many layers of cells. Furthermore, the cell sheets are so flexible and wavy that it is difficult to correctly place them on the surface of the implant body.

Three-dimensional (3D) bioprinting technology is an important technique in tissue engineering because it can help to restore 3D anatomical defects, reconstruct complex organs, and form scaffolds for stem cell differentiation. Recently, complicated 3D structures have been created by living cells using the 3D bioprinter-based 'needle array' system (Yurie et al., 2017). This technology makes it possible to create a preprogramed tubular structure by automatically stacking cellular spheroids on a needle array. The 3Dbioprinted tubular structures derived from multilayered cellular spheroids were strong 
enough to withstand handling, thereby overcoming previous problems with the cell sheet technique.

Stem cells hold great promise as a potential cell source for use in tissue engineering applications because they play crucial roles in tissue development and regeneration with their self-renewal capacity, multipotency, and immunomodulatory effects. In 2004, Seo et al. identified stem cell populations in cells derived from human PDL tissue (Seo et al., 2004). Besides, some paper already reported that stem cells derived from oral cavity may be useful in the fields of regenerative medicine (Trubiani, Marconi, et al., 2019; Trubiani, Pizzicannella, et al., 2019). We then succeeded in developing a multipotent clonal human PDL cell line, line 1-17 (Tomokiyo et al., 2008). This line strongly expresses mesenchymal stem cell-related cell surface markers and embryonic stem cellrelated pluripotency genes, as well as PDL-related molecules. In addition, it has strong proliferation ability because of immortalization during its establishment.

Hydroxyapatite (HA) closely resembles the mineral component of hard tissues in mammals and shows strong bioactive and biocompatible properties. HA-coated dental implant bodies exhibit a greater percentage of initial bone-to-implant contact than noncoated dental implant bodies (Cooley, Van Dellen, Burgess, \& Windeler, 1992).

Furthermore, sintered HA demonstrates excellent physical properties, osteoconductivity, and tissue responses (Munar, Udoh, Ishikawa, Matsuya, \& Nakagawa, 2006). The high porosity also induces cell adhesion, proliferation, and differentiation (Tsuruga, Takita, Itoh, Wakisaka, \& Kuboki, 1997). These characteristics make it suitable for medical applications such as bone implants and fixation components.

In this study, we aimed to create PDL tissue-like tubular structures from line 1-17 cells using 3D bioprinting technology. Furthermore, we combined the structures with cores made from bioactive materials and evaluated the potential of these complexes to function as next-generation biohybrid implants.

\section{Materials and methods}

\section{Cell culture}

Line 1-17 cells were maintained in control medium (CM) composed of alpha-minimum essential medium (Gibco-BRL, Grand Island, NY, USA) supplemented with $50 \mu \mathrm{g} / \mathrm{ml}$ streptomycin and $50 \mathrm{U} / \mathrm{ml}$ penicillin (penicillin-streptomycin solution; Wako Pure Chemical Industries Ltd., Osaka, Japan) and 10\% fetal bovine serum (Biosera, Nuaillé, France) at $37^{\circ} \mathrm{C}$ in a humidified atmosphere of $5 \% \mathrm{CO}_{2}$ and $95 \%$ air. All procedures 
were performed in compliance with the requirements of the Research Ethics Committee at Kyushu University.

\section{Formation of single-cell spheroids}

To form single-cell spheroids (SCSs), line 1-17 cells were exposed to floating cell culture. Briefly, the cells were seeded at a density of $2.5 \times 10^{4}$ cells/well in ultra-low attachment 96-U-well plates (PrimeSurface; Sumitomo Bakelite, Tokyo, Japan) and cultured in CM. The cell morphology was analyzed using the Inspect mode of a Regenova Bio 3D Printer System (Cyfuse, Tokyo, Japan) at 0, 1, 2, 3, and 4 days after the floating culture. The Inspect mode is an automated measurement function that analyzes the morphology of spheroids using a micro-camera equipped on the $3 \mathrm{D}$ printer, and is usually employed to automatically eliminate spheroids whose size and shape are not suitable for stacking on needles. The diameter, roundness, and surface roughness of the SCSs were automatically quantified using Image diffraction software (Cyfuse).

\section{Formation of a 3D-bioprinted tubular structure}

SCSs derived from line 1-17 cells after 2 days of culture were automatically picked from the 96-well plates using a 26-gauge fine suction nozzle equipped on the $3 \mathrm{D}$ printer and inserted into a 9- $\times$ 9-needle array with multiple stainless-steel needles in a container containing phosphate-buffered saline (PBS). SCSs were inserted on the 3D positions of the needle array to form a pre-designed 3D tubular model using a computer system. During printing, the 3D structure was displayed on the monitor of the computer controlling the $3 \mathrm{D}$ printer and constantly monitored by a technician with adjustment of printing parameters such as printing speed and suction force of the nozzle. To generate each 3D tubular structure, a total of 288 SCSs were used. Following the 3D bioprinting, the needle array with the SCSs was set in a perfusion chamber (PC1004; Cyfuse) with $\mathrm{CM}$. The medium was maintained under continuous flow using a circulation cassette tube pump system (SMP23-AS; AS ONE Corporation, Osaka, Japan) with a perfusion rate of $200 \mathrm{ml} / \mathrm{h}$. After 10 days of perfusion culture, the SCSs had fused together, generated abundant extracellular matrix, and formed a solid tubular structure. Following removal of the needle array, the structure was transferred to a $10-\mathrm{cm}$ plate (Corning, Corning, NY, USA) and cultured in CM for 1 day to form a 3D-bioprinted tubular structure (3DTB) derived from line 1-17 cells.

\section{Combination of HA or titanium cores with 3DTBs}


Sintered cylindrical HA cores were generated in the Department of Biomaterials at the Faculty of Dental Science, Kyushu University. Briefly, crushed HA powder (HAP-200; Taihei Chemical Industrial, Osaka, Japan) was placed in a cylindrical stainless steel mold ( $2 \mathrm{~mm}$ in diameter and $2 \mathrm{~mm}$ in height), and pressed at $50 \mathrm{MPa}$ using an oilpressure press machine (MT-50HD; NPa System, Saitama, Japan) for hardening. The pressed powder was then heated at a rate of $5^{\circ} \mathrm{C} / \mathrm{min}$ to $1,100^{\circ} \mathrm{C}$ and kept at this temperature for $6 \mathrm{~h}$ in an electronic furnace (Superburn SBV1515D; Motoyama, Osaka, Japan). After cooling, the sintered cylindrical HA cores were characterized using an Xray diffractometer (XRD) (D8 Advance; Bruker AXS GmbH, Karlsruhe, Germany) operated at $40 \mathrm{kV}$ and $40 \mathrm{~mA}$. Titanium sticks (Nilaco, Tokyo, Japan) cut to the same height as the HA cores were also prepared as cores. The two types of cores were carefully inserted into 3DTBs using sterilized forceps, and the 3DTB-HA core complexes were incubated in CM without the reflux on a $10-\mathrm{cm}$ plate for 7 days. The 3DTB-HA core and 3DTB-titanium core complexes were designated HAC and TIC, respectively. 3DTBs without a core material cultured in CM without the reflux on a 10$\mathrm{cm}$ plate for 7 days were designated WOC. To evaluate the surface texture of the two kinds of core materials, the cores were mounted on suitable stubs with conductive aluminum tape, gold-coated to obtain clearly visible images, and examined with a scanning electron microscope (SEM) (S-3400N; Hitachi High-Technologies Co., Tokyo, Japan) operated at an acceleration voltage of $15 \mathrm{kV}$.

\section{Quantitative real-time RT-PCR analysis}

After core removal, WOC, TIC, and HAC were minced with a sterilized scalpel and immersed in TRIzol Reagent (Invitrogen, Carlsbad, CA, USA) to isolate total RNA. As a control, total RNA was isolated from a line 1-17 cell monolayer cultured for 7 days in CM. First-strand cDNA was generated from $1 \mu \mathrm{g}$ of total RNA using an ExScript RT reagent kit (Takara Bio Inc., Shiga, Japan). Briefly, reverse transcription of total RNA was performed with random 6-mers and ExScript RTase for $15 \mathrm{~min}$ at $42^{\circ} \mathrm{C}$. The reaction was terminated by incubation for $2 \mathrm{~min}$ at $99^{\circ} \mathrm{C}$, followed by $5 \mathrm{~min}$ at $5^{\circ} \mathrm{C}$. PCR amplification was carried out with a KAPA Express Extract Kit (Kapa Biosystems, Woburn, MA, USA) using a Thermal Cycler Dice Real Time System (Takara Bio Inc.) under the following conditions: $95^{\circ} \mathrm{C}$ for $10 \mathrm{~s}$ (initial denaturation), 50 cycles of $95^{\circ} \mathrm{C}$ for $5 \mathrm{~s}$ and $60^{\circ} \mathrm{C}$ for $30 \mathrm{~s}$ (amplification), and a final dissociation protocol of $95^{\circ} \mathrm{C}$ for $15 \mathrm{~s}, 60^{\circ} \mathrm{C}$ for $30 \mathrm{~s}$, and $95^{\circ} \mathrm{C}$ for $15 \mathrm{~s}$. Human $\beta$-actin was amplified as an internal standard. The primer sequences, annealing temperatures, and product sizes for collagen (COL) 1A1, COL3A1, COL12A1, PLAP1, syndecan1 (SDC1), 
vascular endothelial growth factor (VEGF) A, hepatocyte growth factor (HGF), cementum protein 1 (CEMPI), osteocalcin (OCN), and $\beta$-actin are shown in Table 1. The expression levels of the target genes were calculated using $\Delta \Delta C_{t}$ values.

\section{Cryosectioning of 3DTB-core complexes}

Following washing with PBS, WOC, TIC, and HAC were fixed with 4\% paraformaldehyde (Merck Millipore, Darmstadt, Germany) in PBS overnight at $4{ }^{\circ} \mathrm{C}$. After five washes with PBS, the structures were decalcified in $10 \%$ ethylenediaminetetraacetic acid (Wako Pure Chemical Industries Ltd.) for 7 days at $4^{\circ} \mathrm{C}$. The titanium core spontaneously came off from TIC. The HA core did not require removal from HAC because the complex could be sliced sufficiently finely after the decalcification. The fixed structures were washed five times with PBS, sequentially immersed in 10\%, 15\%, and 20\% sucrose (Nacalai Tesque, Kyoto, Japan) in PBS, and immersed in $20 \%$ sucrose in OCT ${ }^{\mathrm{TM}}$ compound (Sakura Finetek, Tokyo, Japan). Each immersion was carried out overnight at $4^{\circ} \mathrm{C}$. After these immersions, the structures were embedded in $\mathrm{OCT}^{\mathrm{TM}}$ compound on dry ice and frozen at $-20^{\circ} \mathrm{C}$ overnight. Before cutting, the frozen samples were placed in the cabinet of a cryostat (CM1900; Leica, Wetzlar, Germany) and left for $30 \mathrm{~min}$ to equilibrate to its temperature. The samples were cut into $7-\mu \mathrm{m}$ sections and mounted on glass slides (Matsunami Glass Industry, Osaka, Japan).

\section{Hematoxylin eosin (HE) staining}

Following drying for $30 \mathrm{~min}$ at room temperature (RT), the sections were stained with Mayer's hematoxylin solution (Wako Pure Chemical Industries Ltd.) for $100 \mathrm{~s}$ at RT. After washing with running tap water for $20 \mathrm{~min}$, the sections were immersed three times in $0.1 \%$ eosin solution (Wako Pure Chemical Industries Ltd.) at RT. Following washing with running tap water for $1 \mathrm{~min}$, the sections were observed with an inverted microscope (BX41; Olympus, Tokyo, Japan).

\section{Live cell distribution analysis}

Viable line 1-17 cells in WOC, TIC, and HAC were detected using NucSpot ${ }^{\mathrm{TM}}$ Live Cell Nuclear Stain (Biotium, Fremont, CA, USA). After drying for 30 min at RT, the sections were exposed to $1 \mu 1 \mathrm{NucSpot}^{\mathrm{TM}}$ Live 488 and incubated for $10 \mathrm{~min}$ at RT. This reagent detects viable cells by specifically staining the DNA in their nuclei. To confirm that the reagent specifically detected living cells, we stained both living and dead line 1-17 cells with this reagent. For this, we employed hydrogen peroxide $\left(\mathrm{H}_{2} \mathrm{O}_{2}\right)$, 
a widely used apoptosis inducer with a broad cytotoxic efficacy for various types of cells (Whittemore, Loo, \& Cotman, 1994). Briefly, monolayer-cultured line 1-17 cells were exposed to $3 \% \mathrm{H}_{2} \mathrm{O}_{2}$ (Wako Pure Chemical Industries Ltd.) for $10 \mathrm{~min}$ to induce apoptosis. Untreated and $\mathrm{H}_{2} \mathrm{O}_{2}$-treated cells were then stained with $1 \mu \mathrm{NucSpot}{ }^{\mathrm{TM}}$ Live 488 solution for $10 \mathrm{~min}$ at RT. All of the stained specimens were observed under a fluorescence microscope (BZ-X710; Keyence, Osaka, Japan).

\section{Immunohistochemical staining}

After the sections were dried for $30 \mathrm{~min}$ at RT, nonspecific antigens were blocked with $2 \%$ bovine serum albumin (BSA) (Nacalai Tesque) in PBS for $1 \mathrm{~h}$ at RT. A rabbit polyclonal anti-HGF antibody (1:500 dilution; Abcam, Cambridge, UK), a rabbit monoclonal anti-VEGFA antibody (1:500 dilution; Abcam), and a rabbit monoclonal anti-SDC1 antibody (1:500 dilution; Abcam) were applied to the sections as primary antibodies. After $1 \mathrm{~h}$ at RT, the sections were washed five times with PBS and incubated with biotinylated anti-rabbit IgG (Nichirei Biosciences Inc., Tokyo, Japan) as the secondary antibody. After $30 \mathrm{~min}$ at RT, the sections were washed five times with PBS and exposed to avidin-peroxidase conjugate (Nichirei Biosciences Inc.) for $30 \mathrm{~min}$ at RT. After the sections were washed five times with PBS, positive staining was visualized using Simple Stain DAB solution (Nichirei Biosciences Inc.). Staining of nuclei was performed with Mayer's hematoxylin solution (Wako Pure Chemical Industries Ltd.).

\section{Masson's trichrome staining assay}

A Masson's trichrome staining kit was purchased from Muto Pure Chemical Company (Tokyo, Japan). Following drying of the sections for 30 min at RT, a mordant containing 5\% potassium dichromate was applied to the sections for $20 \mathrm{~min}$ at RT. After washing with running distilled water for $5 \mathrm{~min}$, Carrazzi's hematoxylin staining solution (Muto Pure Chemical Company) was applied for $15 \mathrm{~min}$ at RT. The sections were washed for 10 min under running water, and then $0.75 \%$ Orange G solution was applied for $1 \mathrm{~min}$ at RT. The sections were rinsed with $1 \%$ aqueous acetic acid solution, followed by application of Masson's blue solution for $5 \mathrm{~min}$ at RT. After rinsing with $1 \%$ aqueous acetic acid solution, $2.5 \%$ phosphotungstic acid solution was applied for 10 min at RT. The sections were rinsed with $1 \%$ aqueous acetic acid solution, and then 4 $\mathrm{g} / \mathrm{L}$ aniline blue solution was applied for $3 \mathrm{~min}$ at RT. After washing with running distilled water and $1 \%$ aqueous acetic acid solution, the sections were observed with the BX41 inverted microscope. 


\section{Picrosirius red staining assay}

Following drying of the sections for 30 min at RT, Carrazzi's hematoxylin staining solution wa applied to the sections for $8 \mathrm{~min}$ at RT. The sections were then washed with running tap water for $10 \mathrm{~min}$, and picrosirius red solution $(1.2 \%$ picric acid [Nacalai Tesque] and $0.1 \%$ direct red 80 [Sigma-Aldrich, Tokyo, Japan]) was applied for $1 \mathrm{~h}$ at RT. After rinsing with 1\% aqueous acetic acid solution (Nacalai Tesque), the sections were observed with the BX41 inverted microscope.

\section{Immunofluorescence staining analysis}

After the sections were dried for $30 \mathrm{~min}$ at RT, nonspecific antigens were blocked with 2\% BSA in PBS for $1 \mathrm{~h}$ at RT. A rabbit polyclonal anti-CEMP1 antibody (1:50 dilution; Atlas Antibodies, Bromma, Sweden), a rabbit polyclonal anti-OCN antibody (1:500 dilution; Invitrogen), a rabbit monoclonal anti-OSX antibody (1:500 dilution; Abcam, Cambridge, UK) and a rabbit polyclonal anti-BMP2 antibody (1:50 dilution; Bioss Antibodies Inc, Massachusetts, USA) were applied to the sections as primary antibodies. After $1 \mathrm{~h}$ at RT, the sections were washed five times with PBS and then incubated with biotinylated anti-rabbit $\operatorname{IgG}$ (Nichirei) as the secondary antibody. After 30 min at RT, the sections were washed five times with PBS and then exposed to fluorescently labeled avidin (Avidin D-FITC conjugate; 1:1,000 dilution; Vector Laboratories, Burlingame, CA, USA) for $30 \mathrm{~min}$ at RT with light shielding. Following washing five times with PBS, cover glasses were mounted on the glass slides. Nuclear staining was performed using Fluoro-KEEPER antifade reagent, non-hardening type with DAPI (Nacalai Tesque).

\section{Statistical analysis}

All experiments were performed in triplicate or quadruplicate. All data are expressed as mean \pm standard deviation. Statistical analyses were performed using Student's unpaired $t$-test for comparisons of two groups and one-way ANOVA followed by the Bonferroni method for comparisons of three or more groups. Values of $p<0.05$ were considered statistically significant.

\section{Results}

\section{SCS formation using line 1-17 cells}

When line 1-17 cells were initially seeded in the 96-U-well plates (day 0), they did not aggregate. However, the cells started to gather at the center of the wells on day 1 (Fig. 
1A [I]) and spontaneously formed SCSs on day 2 (Fig. 1A [II]). The spheroids exhibited an almost identical shape on days 3 and 4 as on day 2 (Fig. 1A [II-IV]). The diameter of the spheroids expanded significantly from day $1(599.7 \pm 9.131 \mu \mathrm{m})$ to day $2(642.3 \pm$ $8.611 \mu \mathrm{m})$, but then decreased significantly on day $3(624.9 \pm 11.94 \mu \mathrm{m})$ and day 4 $(521.5 \pm 8.760 \mu \mathrm{m})$ (Fig. 1B [I]). The spheroids became significantly more round from day 1 through to day 2 and remained stable with no significant difference thereafter (Fig. 1B [II]). The surface roughness of the spheroids was significantly higher on day 1 than on the other days (Fig. 1B [III]).

These results suggest that the growth of the spheroids gradually decreased day by day after their aggregation in 96-well plates, and that they matured for 2 days until their shape became stable. Therefore, the spheroids were termed as SCSs on day 2 and were used as a cell source for the $3 \mathrm{D}$ tubular structure formation.

\section{Three-dimensional tubular structure formation using SCSs}

Approximately 288 SCSs cultured in 96-U-well plates were automatically collected with a fine suction nozzle and placed into needle arrays to form 3D tubular structures (Fig. 2A-D). The structures were designed using needle array software (Fig. 2E, F). SCSs were correctly placed in the needle arrays in accordance with the software design (Fig. 2G, H).

\section{Combination of 3D tubular structures and core materials}

After 10 days of incubation on the needle arrays, the SCSs generated a huge volume of extracellular matrix and integrated with one another (Fig. 3A [I, II]). The 3D-bioprinted tubular structures removed from the needle array and cultured in CM for 1 more day exhibited a solid tubular shape (3DTB; Fig. 3A [III]). During additional culture of 3DTBs, the cells and the extracellular matrix constituting the structure continued to grow toward the inner surface of the lumen. After a further 7 days of culture, 3DTBs without a core material (WOC) lost their lumens and formed solid structures (Fig. 3A [IV]). Cylindrical HA cores were produced by applying high temperature and high pressure to HA powder (Fig. 3B [I, II]). The HA cores were inserted into the lumens of 3DTBs and these complexes were cultured for 7 days (Fig. 3B [III]). Although the inner diameter of 3DTBs was smaller than the outer diameter of the cylindrical HA cores, their flexibility prevented structural collapse when the cores were inserted into the lumens. Complexes of 3DTBs with cylindrical titanium cores (Fig. 3C [I, II]) were also incubated for 7 days (Fig. 3C [III]). The complexes of 3DTBs with cylindrical HA and titanium cores were designated HAC and TIC, respectively. 
The XRD patterns of the HA powder and HA cylindrical cores demonstrated that their peak positions coincided; however, the crystallinity of the cylindrical cores was higher than that of the powder (Fig. 3D). The surface of the HA cores had many irregularities compared with the surface of the titanium cores (Fig. 3E [I, III]). At higher magnification, the surface of the titanium cores appeared relatively dense, whereas the surface of the HA cores was porous (Fig. 3E [II, IV]).

\section{Morphology and live cell distribution analysis of WOC, TIC, and HAC}

The cellular morphology in WOC, TIC, and HAC was investigated by HE staining (Fig. 4A [I-VI]). In WOC, line 1-17 cells were uniformly distributed from the outside to the inside of the structure (Fig. 4 [II]). In TIC and HAC, line 1-17 cells were uniformly distributed from the outside of the structures to the area adjacent to the cores (Fig. 4A [VI]). The contiguous SCSs were firmly integrated with one another and there was no remnant space derived from the needle arrays. The live cell distributions in WOC, TIC, and HAC were investigated by NucSpot staining (Fig. 4B [I-VI]). In WOC, NucSpotpositive cells were distributed in all areas without deviation, although the supply of oxygen and nutrition was expected to be low in the center (Fig. 4B [I, II]). In both TIC and HAC, NucSpot-positive cells were also confirmed from the outside of the structures to the area adjacent to the cores without deviation (Fig. 4B [III-VI]). Monolayercultured line 1-17 cells treated with PBS or $3 \% \mathrm{H}_{2} \mathrm{O}_{2}$ in PBS were also stained with NucSpot (Fig. S1A, B). PBS-treated living line 1-17 cells showed positive staining for NucSpot (Fig. S1A), while $\mathrm{H}_{2} \mathrm{O}_{2}$-treated dead line 1-17 cells were negative (Fig. S1B).

\section{Picrosirius red and Masson's trichrome staining for WOC, TIC and HAC}

Collagen fibrils positive for picrosirius red staining were distributed in all areas of WOC, TIC, and HAC without deviation (Fig. 5A [I-VI]). These results were consistent with the results for HE staining (Fig. 4A [I-VI]) and NucSpot staining (Fig. 4B [I-VI]). Masson's trichrome staining also demonstrated a broad distribution of blue-stained collagen fibrils in WOC, TIC, and HAC (Fig. 5B [I-VI]). Additional red-stained structures were observed in the outer areas of WOC, TIC, and HAC (Fig. 5B [I-VI]). The range of the red-stained area was larger in HAC than in WOC and TIC.

Gene expression of somatic tissue markers in monolayer-cultured line 1-17 cells, WOC, TIC, and HAC

PDL (COL3A1, PLAP1, and SDC1)-, angiogenesis (VEGFA and $H G F)$-, cementum $(C E M P 1)$-, and bone $(O C N)$-related gene expression was investigated by real-time RT- 
PCR in monolayer-cultured line 1-17 cells, WOC, TIC, and HAC (Fig. 6A-G). Expression of these genes was significantly increased in WOC, TIC, and HAC compared with monolayer-cultured cells. However, no significant differences in gene expression were observed between WOC, TIC, and HAC. The expression of PDLrelated collagen genes (COL1A1 and COL12A1) was also investigated. While WOC and TIC expressed COL1A1 at the same level as monolayer-cultured line 1-17 cells, the expression in HAC tended to be higher (Fig. S2A). HAC also showed the highest COL12A1 expression among the four samples (Fig. S2B).

\section{Expression of HGF, SDC1, VEGF, CEMP1, OCN, OSX and BMP2 in WOC, TIC, and HAC}

HGF-, SDC1-, VEGF-, CEMP1-, and OCN-positive cells were detected in WOC, TIC, and HAC. However, the positive cells varied in number and distribution pattern depending on the target proteins and the 3DTB-core complex type. For HGF, a weak positive reaction was observed in the middle lamella and outermost area in WOC and TIC (Fig. 7A [I-IV]), although intense positive staining was confirmed throughout the lamella in HAC (Fig 7A [V, VI]). SDC1-positive cells were mainly found in the outer area of WOC, TIC, and HAC (Fig. 7B [I-VI]). However, a positive reaction was also detected adjacent to the core in HAC (Fig. 7B [V, VI]). Small numbers of VEGFpositive cells were observed in WOC and TIC (Fig. 7C [I-IV]), whereas many positive cells were confirmed in HAC (Fig. 7C [V, VI]). A particularly strong positive reaction was mainly found in the outer area and a slight positive reaction was observed in the area adjacent to the core. No positive reaction was observed for rabbit control IgG (Fig. 7D [I-VI]). CEMP1 was weakly expressed in the outermost cells of WOC and TIC (Fig. 8A [I-VI]). Strong CEMP1 expression was also confirmed in the outermost cells of HAC (Fig. 8A [VII-IX]). In addition, CEMP1 was expressed in cells located at a small distance from the outside (Fig. S3). The outermost cells exhibited slight expression of OCN in WOC and TIC (Fig. 8B [I-VI]), whereas strong expression was observed in HAC (Fig. 8B [VII-IX]). OCN expression was also confirmed in cells located at a small distance from the outside (Fig. S4). Additional fluorescent immunostaining analysis was also performed on OSX and BMP2 as other bone-related factors (Fig. S5 and S6). OSX- and BMP2-positive cells were mainly found in the outer area of WOC, TIC, and HAC (Fig. S5 [A-C] and S6 [A-C]). Rabbit control IgG exhibited no positive reaction (Fig. 8C [I-IX]).

\section{Discussion}


Tissue homeostasis, sensory transmission, and host defense mechanisms against infection do not occur in conventional dental implants because of their lack of PDL tissue. Therefore, the development of a new hybrid implant system that consists of an artificial tooth root with surrounding PDL tissue is highly anticipated. The purpose of this study was to develop a new hybrid implant system with an artificial PDL by attaching a 3D-bioprinted tubular structure made of PDL-derived cells around the implant body material.

To generate 3D-bioprinted tubular structures, the number of line 1-17 cells used for one spheroid was set at $2.5 \times 10^{4}$ based on a previous study (N. I. Moldovan, 2018). This study also stated that in addition to the cellular aggregation in non-adhesive dishes, the extracellular matrices derived from cells were important for the formation of stable spheroids. Besides, they also suggested that the optimal culture period for forming the spheroids varied with the type of cells. Therefore, we measured the diameter, roundness, and surface roughness of the spheroids derived from line 1-17 cells during 4 days of culture. The size and roundness significantly increased and the surface roughness significantly decreased in spheroids cultured for 2 days compared with spheroids incubated for 1 day. However, their size decreased from 2 days to 4 days, while their roundness and surface roughness were unchanged during this period. These results suggested that the growth and aggregation of spheroids derived from line 1-17 cells progressed up to 2 days and stabilized after 2 days. Therefore, we decided to use the spheroids at 2 days after seeding for the formation of 3D-bioprinted tubular structures in this study. In addition, some recent reports about 3D printing technique used multiple kinds of cells for the formation of cellular spheroids (L. Moldovan et al., 2017; Ong et al., 2017), however this study applied only one kind of cell to produce spheroids. Therefore, the spheroids created in this study was called SCSs.

To generate a biohybrid implant, we combined the 3DTBs with a titanium core. Titanium is a bioinert material that is the most favored conventional implant material because of its high levels of mechanical strength, biocompatibility, and osseointegration (Brånemark et al., 1977). Various types of cells were reported to attach to the titanium surface, and PDL stem cells were shown to adhere to titanium with a high proliferation rate (Heo, Um, Kim, Park, \& Seo, 2011). Furthermore, Washio et al. cultured PDLderived cell sheets on titanium implant bodies and demonstrated their tight integration (Washio et al., 2018). We also included HA as a core material for 3DTBs because of its superior bioactive properties, osteoconductivity, and chemical similarity to the mineral of hard tissue (Munar et al., 2006). Craig and LeGeros demonstrated that PDL cells could attach to the HA surface and proliferate there while synthesizing various types of 
proteins, similar to the case for cells attached to a titanium surface (Craig \& LeGeros, 1999). Based on these results, we hypothesized that titanium and HA were suitable core materials for attachment and proliferation of line 1-17 cells. The cylindrical HA cores were developed by pressing and sintering HA powder. XRD analysis demonstrated that the peaks for HA powder and HA cores almost corresponded, indicating that the HA cores retained the characteristics of HA even after being pressed and sintered.

Oxygen concentration is one of the most important parameters for 3D cell culture. We had predicted that line 1-17 cells located away from the surface of WOC, TIC, and HAC would undergo apoptotic and necrotic cell death because of a poor oxygen supply. However, HE staining and live cell staining revealed that viable line 1-17 cells were densely distributed in all of these structures. Arai et al. developed tubular cardiac structures using the same method employed in this study (Arai et al., 2018) and revealed that most cells in the inner region of the tubular constructs survived. They used a bioreactor to culture the tubular structures, as we did in this study. Bioreactors are known to improve the oxygen supply to cells in the 3D environment via perfusion of the culture medium (Nishi, Matsumoto, Dong, \& Uemura, 2013). These results suggested that line 1-17 cells in WOC, TIC, and HAC received a generous supply of oxygen under perfusion culture, and thus most cells survived regardless of their distance from the surface of these structures.

Collagen is an abundant molecule that is important for the stability, functional ability, strength, and physical characteristics of various tissues in mammals. Collagen fibers are abundant in PDL tissue and arranged in bundles that are critically important for the structure and function of the tissue (Kaku \& Yamauchi, 2014). Our findings demonstrated abundant collagen distribution in WOC, TIC, and HAC using picrosirius red and Masson's trichrome staining. These results are consistent with a previous report (Itoh et al., 2019) that generated 3D-bioprinted vascular-like structures derived from human fibroblasts. Collagen in PDL tissue is divided into three groups: fibril-forming collagen (collagen type I [COL-I], collagen type III [COL-III], and collagen type V [COL-V]), non-fibril-forming collagen (collagen type VI [COL-VI]), and fibrilassociated collagen with interrupted triple helices (collagen type XII [COL-XII] and collagen type XIV [COL-XIV]) (Nemoto, Kajiya, Tsuzuki, Takahashi, \& Okabe, 2010). We compared the gene expression levels of various collagens in WOC, TIC, HAC, and monolayer-cultured line 1-17 cells, and demonstrated significant upregulation of COL3A1 in the 3D structures compared with the monolayer-cultured cells. COL3A1 gene mutation induced the formation of fragile blood vessels and skin, suggesting that COL3A1 is important for the development and homeostasis of organs (Chiarelli, Carini, 
Zoppi, Ritelli, \& Colombi, 2018). Liu et al. reported that a lack of COL3A1 inhibited normal collagen fibrillogenesis and resulted in defective mature COL1 fibrils (Liu, Wu, Byrne, Krane, \& Jaenisch, 1997). These results indicated that elevation of COL3A1 expression may regulate the formation of other collagens via promotion of their fibrillogenesis and maturation in the 3D structures.

Red-stained structures were confirmed after Masson's trichrome staining in WOC, TIC, and HAC. Interestingly, these results were consistent with the findings for immunofluorescence and histochemical analyses of CEMP and OCN. CEMP1 was first identified as a specific marker of cementoblast-related cells (Alvarez-Pérez, Narayanan, Zeichner-David, Rodríguez Carmona, \& Arzate, 2006). Additionally, 3D-aggregated human PDL cells differentiated into cementoblasts under exposure to CEMP1 (Hoz et al., 2012). OCN is the most abundant non-collagenous bone matrix protein and is generally regarded as a marker of bone formation (Falkenbach \& Herold, 2002). Its expression was also confirmed in cementoblasts at the gene and protein levels (Ma et al., 2019; Thomson, Berry, Somerman, \& Kirkwood, 2003). Moreover, cementum and cementoblasts exhibited a red color when they were exposed to Masson's trichrome staining (Chen et al., 2016; Qiu et al., 2020). Based on these results, the red-stained structures observed in WOC, TIC, and HAC were confirmed as newly-formed cementum and cementoblast-like cells.

We also investigated the expression of PDL-, angiogenesis-, cementum-, and bonerelated genes in WOC, TIC, HAC, and monolayer-cultured line 1-17 cells. Expression of these genes was significantly increased in WOC, TIC, and HAC compared with monolayer-cultured line 1-17 cells. Stem cells in spheroid culture were reported to maintain their multipotency (Huang, Dai, Yen, \& Hsu, 2011), and previous studies demonstrated upregulation of angiogenesis- and bone-related gene expression in human adipose tissue-derived stem cells exposed to 3D culture compared with monolayer culture (Cheng, Chen, Li, \& Young, 2013; Rumiński, Kalaszczyńska, Długosz, \& Lewandowska-Szumiel, 2019). The present results suggested that line 1-17 cells preserved their multipotency in SCSs and started to differentiate into PDL cells, vascular-, cementoblast-, and osteoblast-like cells after 3D bioprinting.

Immunohistochemical staining also revealed the expression of SDC1, HGF, and VEGF in WOC, TIC, and HAC. However, expression of these proteins was mainly confirmed in the outermost area of WOC and TIC, but observed in both the middle lamella and outermost area in HAC. The difference in staining patterns may be explained by the porosity of the core material. Our SEM analysis demonstrated that the surface of the titanium core was dense, whereas the surface of the HA core was porous. A previous 
study suggested that a structure with high porosity like HA was important for cell adhesion, proliferation, and differentiation (Tsuruga et al., 1997). Moreover, bone morphogenetic proteins rapidly diffused when applied without a carrier but induced osteogenesis when applied with porous HA as a carrier. These findings indicate that a HA core would deliver various signaling molecules and promote the differentiation of a wide range of cells in HAC. Moreover, the location of staining for CEMP1, OCN, OSX, and BMP2 tended to be far from the middle lamella in WOC and TIC. This finding was consistent with the results of Masson's trichrome staining. Shishido et al. created aggregate from ovarian cancer cell lines and co-cultured with mesothelial cells (Shishido et al., 2018). They demonstrated that CD44- and CD133-positive cells were located at the periphery at $24 \mathrm{~h}$ and occupied almost the entire aggregate at 7 days. This result suggested that the differentiation of cells in cellular aggregates began on their outside, thereafter cells located their inside started to differentiate. Therefore, our results indicated that line 1-17 located at the periphery of WOC and TIC could start to differentiate into osteoblast- and/or cementoblast-like cells, and cells residing in the central area would remain undifferentiated state under the culture condition that we used in this study.

The findings of our study suggest that HA cores may be suitable for the implant body when combined with 3D structures. However, the medium that we used in this study did not include osteoinductive factors, therefore a small number of line with HA cores could differentiate into osteoblast- and cementoblast-like cells. Moreover, in vivo, there are many external factors that are difficult to reproduce in vitro, including the factors of bite force and the alveolar bone tissue around the implanted structure. Therefore, additional in vivo experiments are needed to determine suitable core materials for use with 3D structures.

\section{Conclusion}

The combination of 3D-printed structures produced by line 1-17 cells and HA cores exhibited high cell viability, included abundant collagen fibers, and expressed factors strongly associated with PDL tissue. Our results suggest that these 3D structures could promote PDL formation and become a part of new biohybrid implant system.

\section{Acknowledgments}

This work was financially supported by Grants-in-Aid for Scientific Research (Project Nos. JP18K19651, JP17H04385, and 17H01598 from the Japan Society for the Promotion of Science. We thank Helen Jeays, BDSc AE, and Alison Sherwin, PhD, 
from Edanz Group (https://en-author-services.edanzgroup.com/ac) for editing a draft of this manuscript.

\section{References}

Alvarez-Pérez, M. A., Narayanan, S., Zeichner-David, M., Rodríguez Carmona, B., \& Arzate, H. (2006). Molecular cloning, expression and immunolocalization of a novel human cementum-derived protein (CP-23). Bone, 38(3), 409-419. doi:10.1016/j.bone.2005.09.009

Arai, K., Murata, D., Verissimo, A. R., Mukae, Y., Itoh, M., Nakamura, A., . . . Nakayama, K. (2018). Fabrication of scaffold-free tubular cardiac constructs using a Bio-3D printer. PLoS One, 13(12), e0209162. doi:10.1371/journal.pone.0209162

Brånemark, P. I., Hansson, B. O., Adell, R., Breine, U., Lindström, J., Hallén, O., \& Ohman, A. (1977). Osseointegrated implants in the treatment of the edentulous jaw. Experience from a 10-year period. Scand J Plast Reconstr Surg Suppl, 16, $1-132$.

Carnes, D. L., Maeder, C. L., \& Graves, D. T. (1997). Cells with osteoblastic phenotypes can be explanted from human gingiva and periodontal ligament. $J$ Periodontol, 68(7), 701-707. doi:10.1902/jop.1997.68.7.701

Chen, X., Liu, Y., Miao, L., Wang, Y., Ren, S., Yang, X., . . S Sun, W. (2016). Controlled release of recombinant human cementum protein 1 from electrospun multiphasic scaffold for cementum regeneration. Int J Nanomedicine, 11, 31453158. doi:10.2147/ijn.S104324

Cheng, N. C., Chen, S. Y., Li, J. R., \& Young, T. H. (2013). Short-term spheroid formation enhances the regenerative capacity of adipose-derived stem cells by promoting stemness, angiogenesis, and chemotaxis. Stem Cells Transl Med, 2(8), 584-594. doi:10.5966/sctm.2013-0007

Chiarelli, N., Carini, G., Zoppi, N., Ritelli, M., \& Colombi, M. (2018). Transcriptome analysis of skin fibroblasts with dominant negative COL3A1 mutations provides molecular insights into the etiopathology of vascular Ehlers-Danlos syndrome. PLoS One, 13(1), e0191220. doi:10.1371/journal.pone.0191220

Cooley, D. R., Van Dellen, A. F., Burgess, J. O., \& Windeler, A. S. (1992). The advantages of coated titanium implants prepared by radiofrequency sputtering from hydroxyapatite. J Prosthet Dent, 67(1), 93-100. doi:10.1016/00223913(92)90057-h 
Craig, R. G., \& LeGeros, R. Z. (1999). Early events associated with periodontal connective tissue attachment formation on titanium and hydroxyapatite surfaces. J Biomed Mater Res, 47(4), 585-594. doi:10.1002/(sici)10974636(19991215)47:4<585::aid-jbm16>3.0.co;2-o

Falkenbach, A., \& Herold, M. (2002). Osteocalcin: a marker of disease activity in ankylosing spondylitis? Ann Rheum Dis, 61(1), 92. doi:10.1136/ard.61.1.92

Heo, Y. Y., Um, S., Kim, S. K., Park, J. M., \& Seo, B. M. (2011). Responses of periodontal ligament stem cells on various titanium surfaces. Oral Dis, 17(3), 320-327. doi:10.1111/j.1601-0825.2010.01728.x

Hoz, L., Romo, E., Zeichner-David, M., Sanz, M., Nuñez, J., Gaitán, L., . . Arzate, H. (2012). Cementum protein 1 (CEMP1) induces differentiation by human periodontal ligament cells under three-dimensional culture conditions. Cell Biol Int, 36(2), 129-136. doi:10.1042/cbi20110168

Huang, G. S., Dai, L. G., Yen, B. L., \& Hsu, S. H. (2011). Spheroid formation of mesenchymal stem cells on chitosan and chitosan-hyaluronan membranes. Biomaterials, 32(29), 6929-6945. doi:10.1016/j.biomaterials.2011.05.092

Itoh, M., Mukae, Y., Kitsuka, T., Arai, K., Nakamura, A., Uchihashi, K., . . . Kobayashi, E. (2019). Development of an immunodeficient pig model allowing long-term accommodation of artificial human vascular tubes. Nat Commun, 10(1), 2244. doi:10.1038/s41467-019-10107-1

Kaku, M., \& Yamauchi, M. (2014). Mechano-regulation of collagen biosynthesis in periodontal ligament. J Prosthodont Res, 58(4), 193-207. doi:10.1016/j.jpor.2014.08.003

Lee, D. J., Lee, J. M., Kim, E. J., Takata, T., Abiko, Y., Okano, T., . . Jung, H. S. (2017). Bio-implant as a novel restoration for tooth loss. Sci Rep, 7(1), 7414. doi:10.1038/s41598-017-07819-z

Lin, Y., Gallucci, G. O., Buser, D., Bosshardt, D., Belser, U. C., \& Yelick, P. C. (2011). Bioengineered periodontal tissue formed on titanium dental implants. J Dent Res, 90(2), 251-256. doi:10.1177/0022034510384872

Liu, X., Wu, H., Byrne, M., Krane, S., \& Jaenisch, R. (1997). Type III collagen is crucial for collagen I fibrillogenesis and for normal cardiovascular development. Proc Natl Acad Sci U S A, 94(5), 1852-1856. doi:10.1073/pnas.94.5.1852

Ma, L., Wang, X., Liu, H., Jiang, C., Liao, H., Xu, S., . . Cao, Z. (2019). CXXC5 Mediates P. gingivalis-suppressed Cementoblast Functions Partially via MAPK Signaling Network. Int J Biol Sci, 15(8), 1685-1695. doi:10.7150/ijbs.35419 
Moldovan, L., Barnard, A., Gil, C. H., Lin, Y., Grant, M. B., Yoder, M. C., . . . Moldovan, N. I. (2017). iPSC-Derived Vascular Cell Spheroids as Building Blocks for Scaffold-Free Biofabrication. Biotechnol J, 12(12). doi:10.1002/biot.201700444

Moldovan, N. I. (2018). Progress in scaffold-free bioprinting for cardiovascular medicine. J Cell Mol Med, 22(6), 2964-2969. doi:10.1111/jcmm.13598

Munar, M. L., Udoh, K., Ishikawa, K., Matsuya, S., \& Nakagawa, M. (2006). Effects of sintering temperature over 1,300 degrees $\mathrm{C}$ on the physical and compositional properties of porous hydroxyapatite foam. Dent Mater J, 25(1), 51-58. doi:10.4012/dmj.25.51

Nemoto, T., Kajiya, H., Tsuzuki, T., Takahashi, Y., \& Okabe, K. (2010). Differential induction of collagens by mechanical stress in human periodontal ligament cells. Arch Oral Biol, 55(12), 981-987. doi:10.1016/j.archoralbio.2010.08.004

Nishi, M., Matsumoto, R., Dong, J., \& Uemura, T. (2013). Engineered bone tissue associated with vascularization utilizing a rotating wall vessel bioreactor. $J$ Biomed Mater Res A, 101(2), 421-427. doi:10.1002/jbm.a.34340

Ong, C. S., Fukunishi, T., Zhang, H., Huang, C. Y., Nashed, A., Blazeski, A., . . . Hibino, N. (2017). Biomaterial-Free Three-Dimensional Bioprinting of Cardiac Tissue using Human Induced Pluripotent Stem Cell Derived Cardiomyocytes. Sci Rep, 7(1), 4566. doi:10.1038/s41598-017-05018-4

Qiu, J., Wang, X., Zhou, H., Zhang, C., Wang, Y., Huang, J., . . Song, A. (2020). Enhancement of periodontal tissue regeneration by conditioned media from gingiva-derived or periodontal ligament-derived mesenchymal stem cells: a comparative study in rats. Stem Cell Res Ther, 11(1), 42. doi:10.1186/s13287019-1546-9

Rumiński, S., Kalaszczyńska, I., Długosz, A., \& Lewandowska-Szumieł, M. (2019). Osteogenic differentiation of human adipose-derived stem cells in 3D conditions - comparison of spheroids and polystyrene scaffolds. Eur Cell Mater, 37, 382401. doi:10.22203/eCM.v037a23

Seo, B. M., Miura, M., Gronthos, S., Bartold, P. M., Batouli, S., Brahim, J., . . Shi, S. (2004). Investigation of multipotent postnatal stem cells from human periodontal ligament. Lancet, 364(9429), 149-155. doi:10.1016/s0140-6736(04)16627-0

Shimono, M., Ishikawa, T., Ishikawa, H., Matsuzaki, H., Hashimoto, S., Muramatsu, T., ... Inoue, T. (2003). Regulatory mechanisms of periodontal regeneration. Microsc Res Tech, 60(5), 491-502. doi:10.1002/jemt.10290 
Shishido, A., Mori, S., Yokoyama, Y., Hamada, Y., Minami, K., Qian, Y., . . . Yamamoto, H. (2018). Mesothelial cells facilitate cancer stem-like properties in spheroids of ovarian cancer cells. Oncol Rep, 40(4), 2105-2114. doi:10.3892/or.2018.6605

Takeuchi, R., Kuruma, Y., Sekine, H., Dobashi, I., Yamato, M., Umezu, M., . . Okano, T. (2016). In vivo vascularization of cell sheets provided better long-term tissue survival than injection of cell suspension. J Tissue Eng Regen Med, 10(8), 700710. doi:10.1002/term.1854

Thomson, T. S., Berry, J. E., Somerman, M. J., \& Kirkwood, K. L. (2003). Cementoblasts maintain expression of osteocalcin in the presence of mineral trioxide aggregate. J Endod, 29(6), 407-412. doi:10.1097/00004770-20030600000007

Tomokiyo, A., Maeda, H., Fujii, S., Wada, N., Shima, K., \& Akamine, A. (2008). Development of a multipotent clonal human periodontal ligament cell line. Differentiation, 76(4), 337-347. doi:10.1111/j.1432-0436.2007.00233.x

Trubiani, O., Marconi, G. D., Pierdomenico, S. D., Piattelli, A., Diomede, F., \& Pizzicannella, J. (2019). Human Oral Stem Cells, Biomaterials and Extracellular Vesicles: A Promising Tool in Bone Tissue Repair. Int J Mol Sci, 20(20). doi:10.3390/ijms20204987

Trubiani, O., Pizzicannella, J., Caputi, S., Marchisio, M., Mazzon, E., Paganelli, R., .. . Diomede, F. (2019). Periodontal Ligament Stem Cells: Current Knowledge and Future Perspectives. Stem Cells Dev, 28(15), 995-1003. doi:10.1089/scd.2019.0025

Tsuruga, E., Takita, H., Itoh, H., Wakisaka, Y., \& Kuboki, Y. (1997). Pore size of porous hydroxyapatite as the cell-substratum controls BMP-induced osteogenesis. J Biochem, 121(2), 317-324. doi:10.1093/oxfordjournals.jbchem.a021589

Washio, K., Tsutsumi, Y., Tsumanuma, Y., Yano, K., Srithanyarat, S. S., Takagi, R., ... Ishikawa, I. (2018). In Vivo Periodontium Formation Around Titanium Implants Using Periodontal Ligament Cell Sheet. Tissue Eng Part A, 24(15-16), 1273-1282. doi:10.1089/ten.TEA.2017.0405

Whittemore, E. R., Loo, D. T., \& Cotman, C. W. (1994). Exposure to hydrogen peroxide induces cell death via apoptosis in cultured rat cortical neurons. Neuroreport, 5(12), 1485-1488. doi:10.1097/00001756-199407000-00019

Yurie, H., Ikeguchi, R., Aoyama, T., Kaizawa, Y., Tajino, J., Ito, A., . . Matsuda, S. (2017). The efficacy of a scaffold-free Bio 3D conduit developed from human 
fibroblasts on peripheral nerve regeneration in a rat sciatic nerve model. PLoS One, 12(2), e0171448. doi:10.1371/journal.pone.0171448 


\section{Figures}
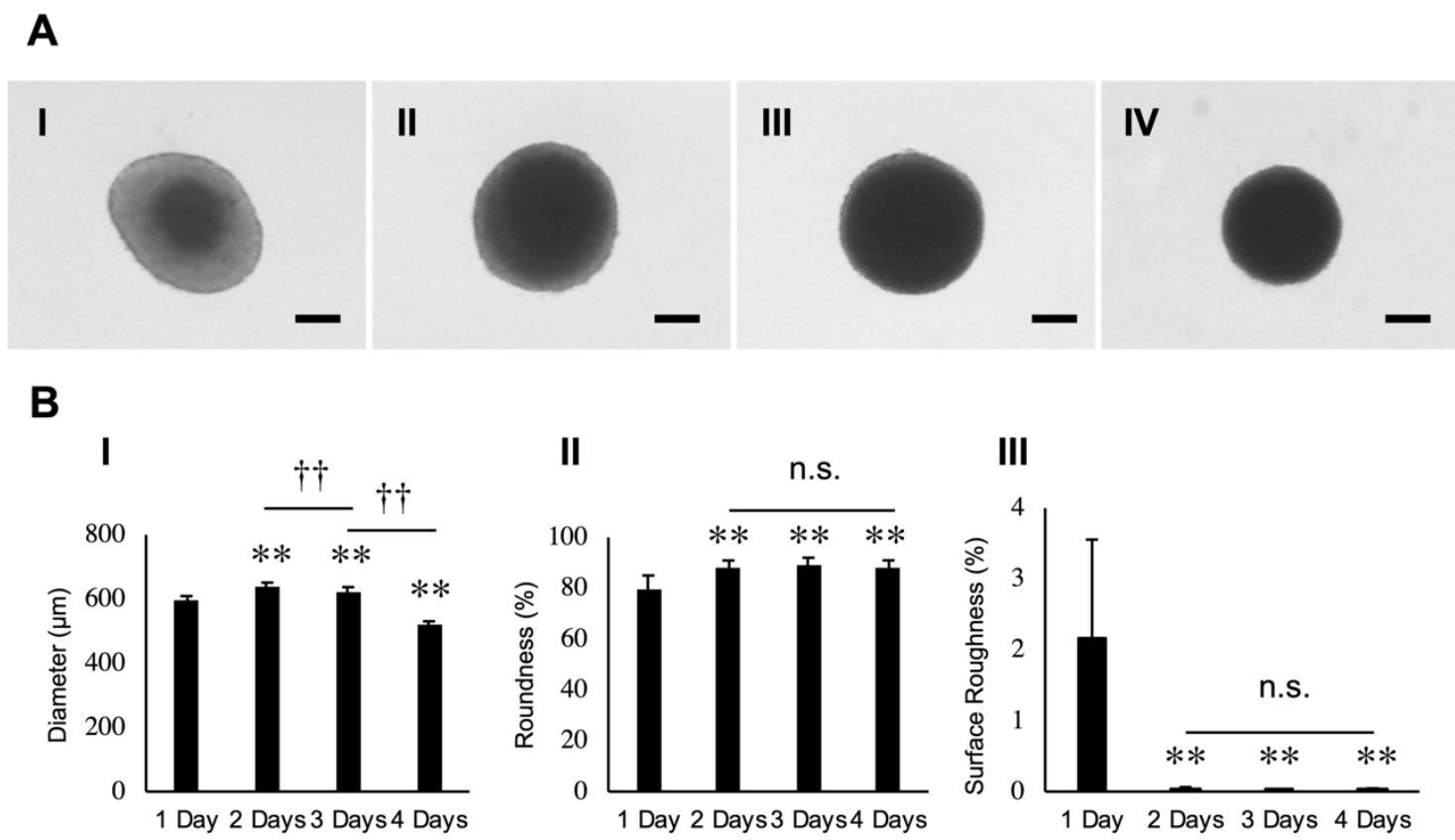

Figure 1. Morphological analysis of single cellular spheroids derived from line 1-17

Figure 1. Morphological analysis of single cellular spheroids derived from cell line 1-17 cells

(A) Phase-contrast microscopic images of line 1-17 cell-derived single cellular spheroids. Line $1-17$ cells $\left(2.5 \times 10^{4}\right.$ cells/well $)$ were seeded on $96-U-w e l l$ plates and cultured in control medium for 1 day (I), 2 days (II), 3 days (III), and 4 days (IV). Representative images are shown. Scale bars $=200 \mu \mathrm{m}$. (B) Diameter (I), roundness (II), and surface roughness (III) of single cellular spheroids incubated for 1, 2, 3, and 4 days. Values are means \pm SD from three independent experiments. ${ }^{*} p<0.01$ vs. 1 day, ${ }^{\dagger \dagger} \mathrm{p}<0.01(\mathrm{n}=96)$. n.s., not significant. 
A

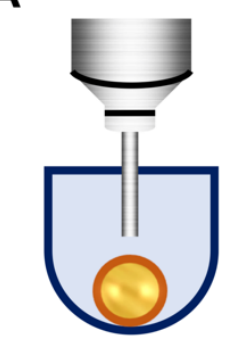

E

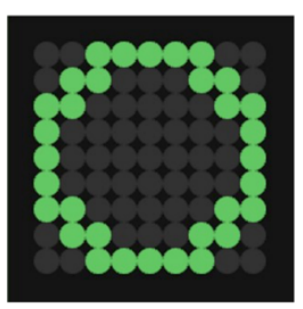

B

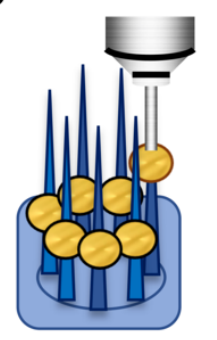

$\mathbf{F}$

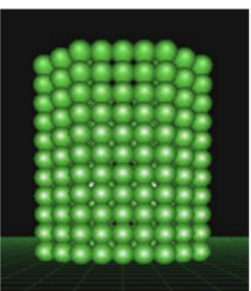

C

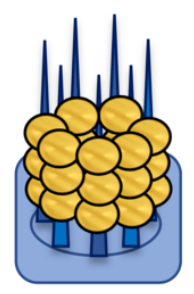

G

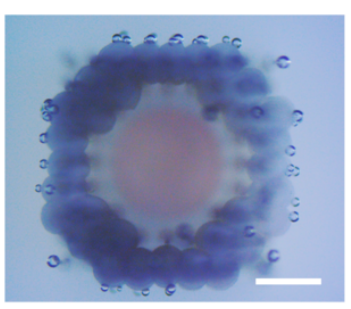

D

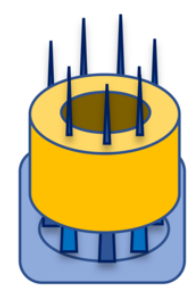

H

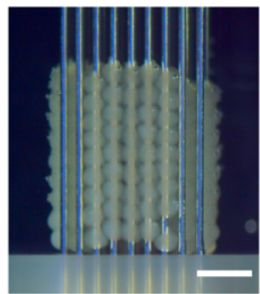

Figure 2. Three-dimensional tubular structure formation using SCSs

Figure 2. Three-dimensional (3D) tubular structure formation using singular cellular spheroids (SCSs)

(A-F) Schematic images of 3D tubular structure formation. (A) Spheroids cultured in a 96-U-well plate are collected with a fine suction nozzle. (B) The spheroids are placed onto an appropriate needle array according to a 3D design composed with the needle array software. (C) The 3D-bioprinted spheroids are cultured on the needle array for structural maturation. (D) After culture, the spheroids integrate with one another and generate a cell-derived 3D tubular structure. Top (E) and side (F) images of the software-composed 3D design are shown. $(\mathrm{G}, \mathrm{H})$ Representative images of the 3Dprinted SCSs on the needle array. Top $(\mathrm{G})$ and side $(\mathrm{H})$ images are shown. Scale bars $=$ $1 \mathrm{~mm}$. 


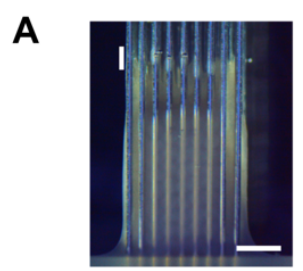

B

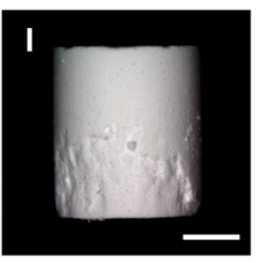

C

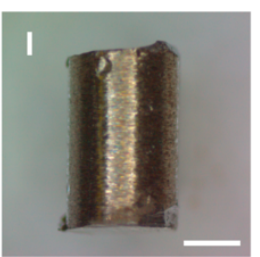

D

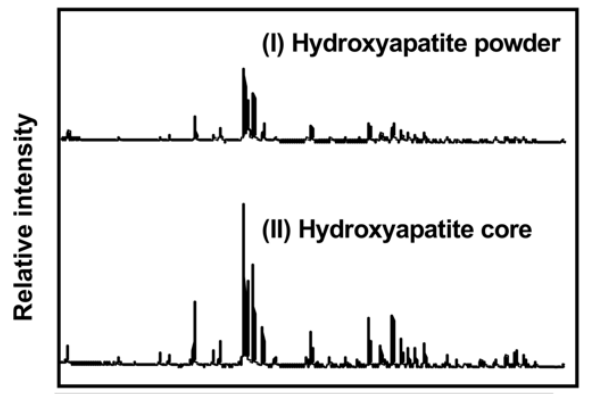

$\begin{array}{lllllllllllll}10 & 15 & 20 & 25 & 30 & 35 & 40 & 45 & 50 & 55 & 60 & 65 & 70\end{array}$ $2 \theta$ (degree)
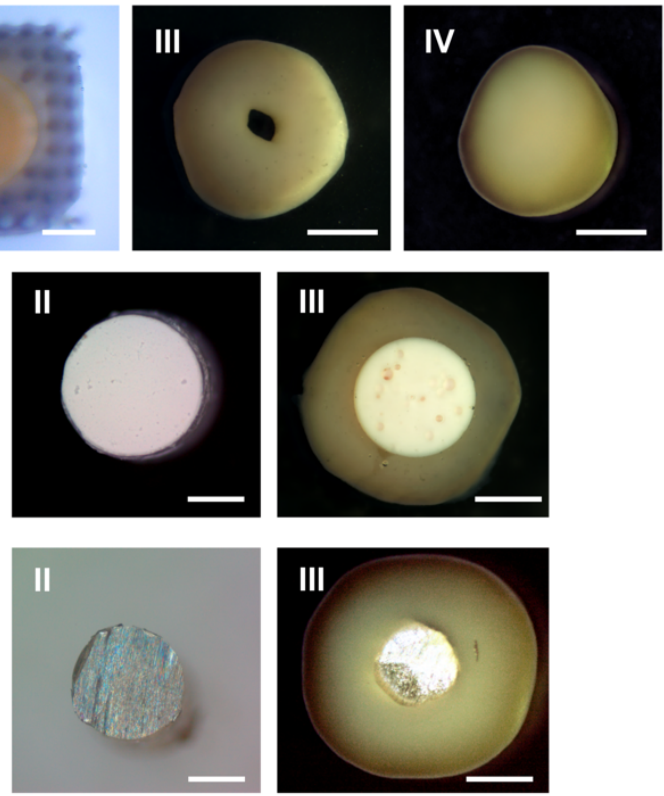

E
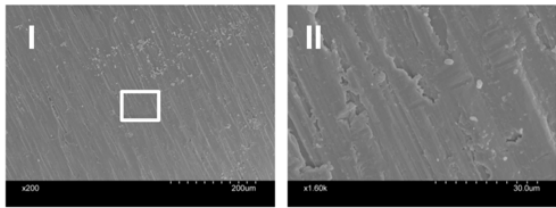

III
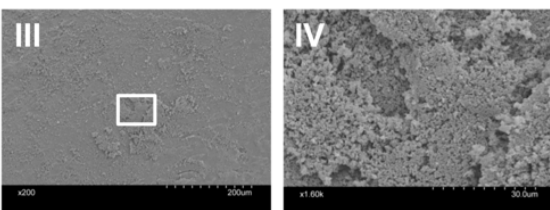

Figure 3. Representative view of structures and evaluation of core materials

Figure 3. Representative images of structures and evaluation of core materials

(A) Representative side (I) and top (II) images of spheroids incubated for 10 days on the needle array. Top view of a 3D tubular structure (3DTB) just after being pulled out from the needle array (III) and after a further 7 days of culture on a $10-\mathrm{cm}$ dish without a core material (WOC; IV). (B) Representative side (I) and top (II) images of a cylindrical hydroxyapatite core and a top view of a 3DTB after 7 days of culture with a hydroxyapatite core (HAC; III). (C) Representative side (I) and top (II) images of a cylindrical titanium core and a top view of a 3DTB after 7 days of culture with a titanium core (TIC; III). Scale bars $=1 \mathrm{~nm}$. (D) X-ray diffractometer patterns of hydroxyapatite powder (I) and a hydroxyapatite core (II). (E) Representative scanning electron micrographs of a titanium core (I, II) and a hydroxyapatite core (III, IV) at 
magnifications of $\times 200$ and $\times 1,600$. II and IV are highly magnified views of the boxed areas in I and III, respectively.
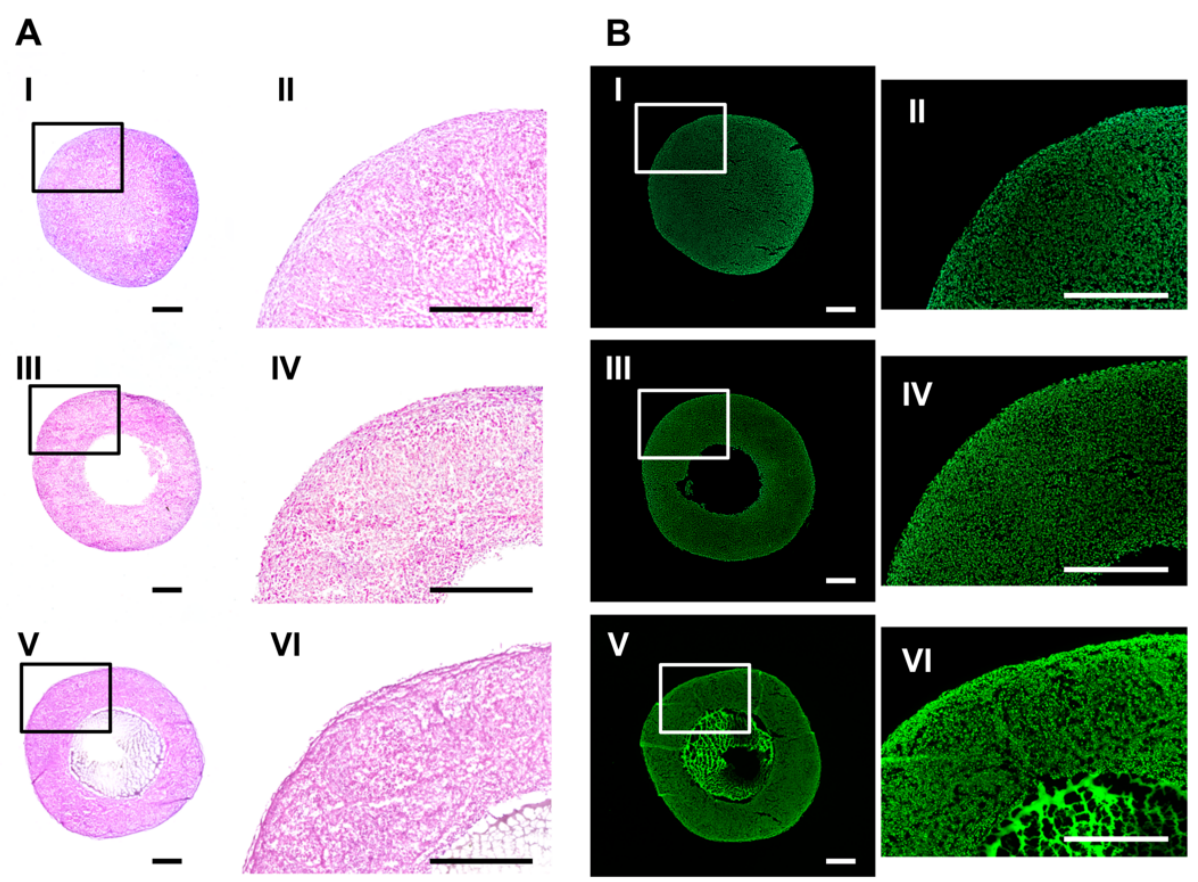

Figure 4. Morphological and live cell distribution analysis for WOC, TIC and HAC

Figure 4. Morphological and live cell distribution analyses in WOC, TIC, and HAC

(A, B) Images of hematoxylin and eosin (A) and NucSpot (B) staining in WOC (I, II), TIC (III, IV), and HAC (V, VI). II, IV, and VI are highly magnified views of the boxed areas in I, III, and V, respectively. Experiments were performed in duplicate.

Representative images are shown. Green indicates NucSpot-positive living cells. Scale bars $=500 \mu \mathrm{m}$. WOC: 3D tubular structure without a core material; TIC: 3D tubular structure with a titanium core; HAC: 3D tubular structure with a hydroxyapatite core. 
A

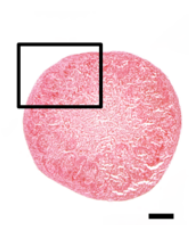

III

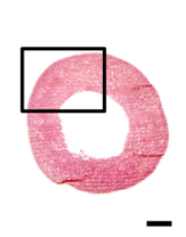

V

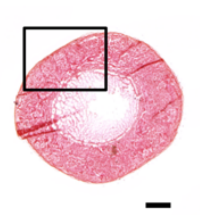

II

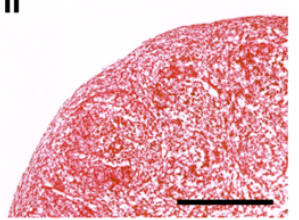

IV

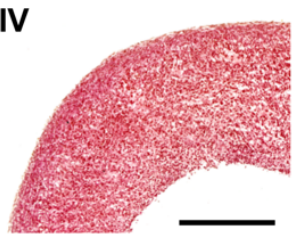

VI

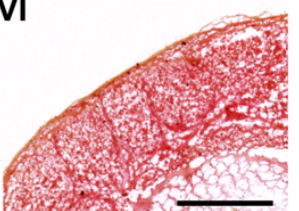

B

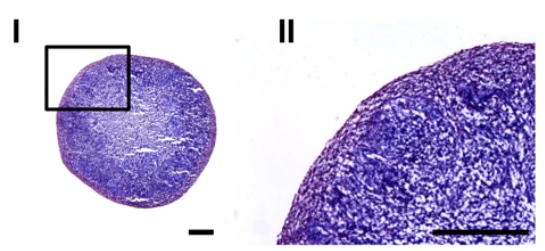

III

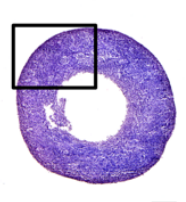

IV

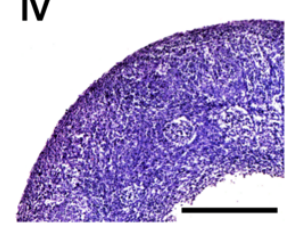

v

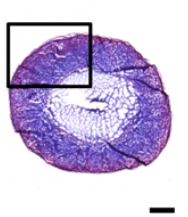

VI

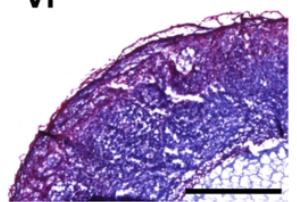

Figure 5. Picro-Sirius Red and Masson's trichrome staining for WOC, TIC and HAC

Figure 5. Picrosirius red and Masson's trichrome staining in WOC, TIC, and HAC (A, B) Images of picrosirius red (A) and Masson's trichrome (B) staining in WOC (I, II), TIC (III, IV), and HAC (V, VI). II, IV, and VI are highly magnified views of the boxed areas in I, III, and V, respectively. Experiments were performed in duplicate. Representative images are shown. After picrosirius red staining, a positive reaction was confirmed in all areas of WOC, TIC, and HAC. After Masson's trichrome staining, blue-stained matrices were broadly distributed in WOC, TIC, and HAC. Red-stained structures were confirmed in the outer areas. Scale bars $=500 \mu \mathrm{m}$. WOC: 3D tubular structure without a core material; TIC: 3D tubular structure with a titanium core; HAC: 3D tubular structure with a hydroxyapatite core. 

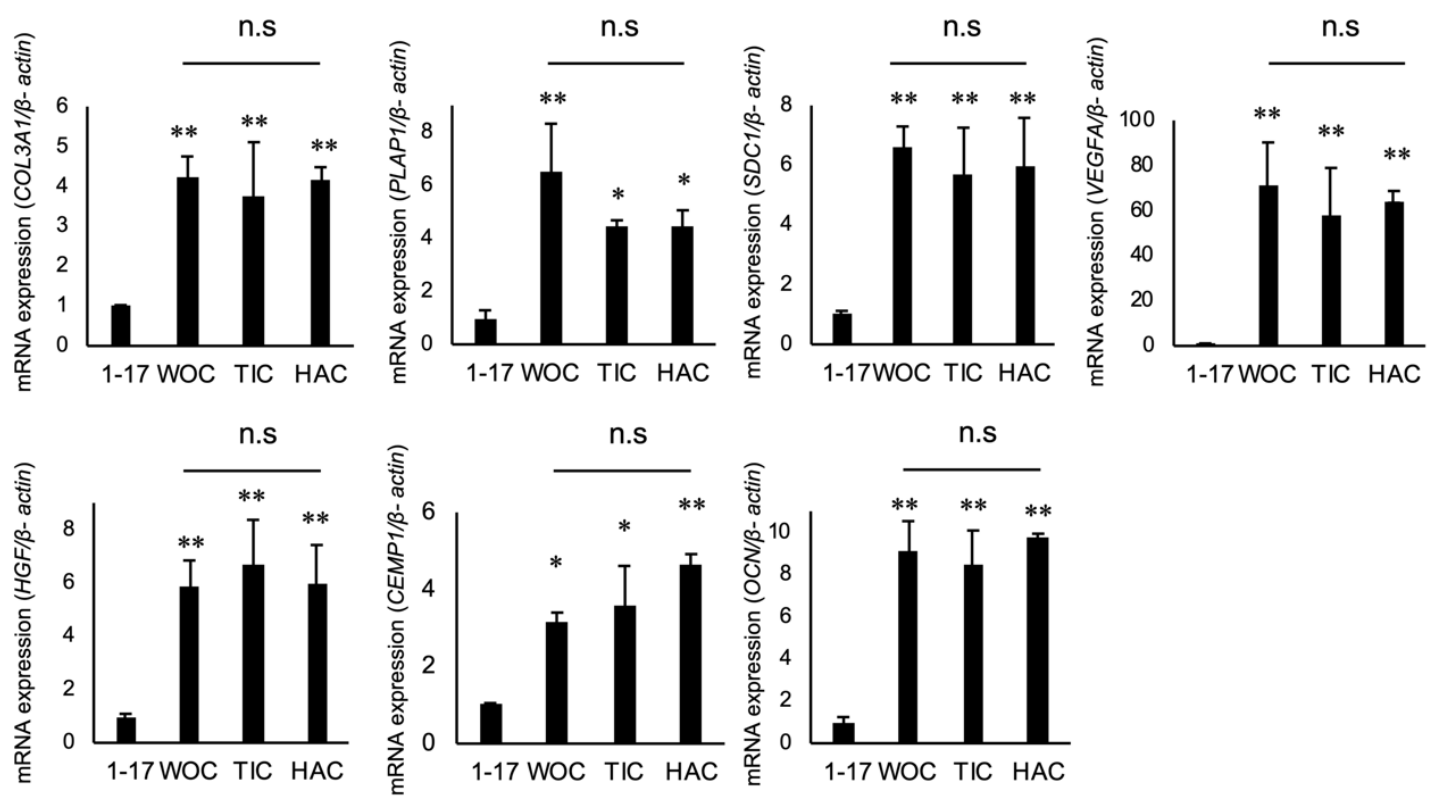

Figure 6. Gene expression analysis for line 1-17, WOC, TIC and HAC

Figure 6. Gene expression analysis in line 1-17 cells, WOC, TIC, and HAC PDL (COL3A1, PLAP1, and SDC1)-, angiogenesis (VEGFA and HGF)-, cementum $(C E M P 1)$-, and bone $(O C N)$-related gene expression in monolayer-cultured line 1-17 cells, WOC, TIC, and HAC. These gene expression levels were compared with realtime RT-PCR findings. Values are means \pm SD from three independent experiments. Line 1-17: monolayer-cultured line 1-17 cells; WOC: 3D tubular structure without a core material; TIC: 3D tubular structure with a titanium core; HAC: 3D tubular structure with a hydroxyapatite core. ${ }^{*} \mathrm{p}<0.05,{ }^{*} \mathrm{p}<0.01$ vs. line $1-17$ cells $(\mathrm{n}=3)$. 
A

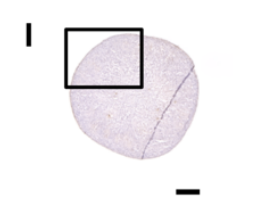

III

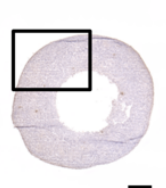

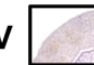

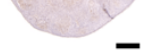

C

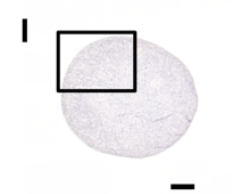

III
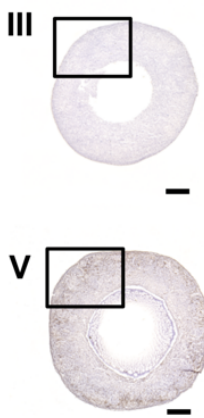

II

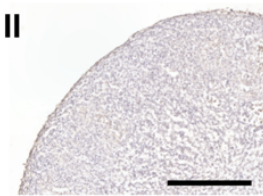

IV

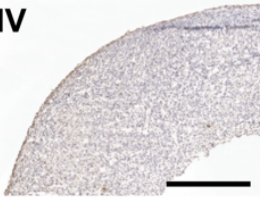

VI

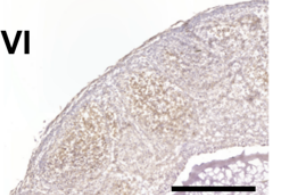

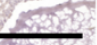

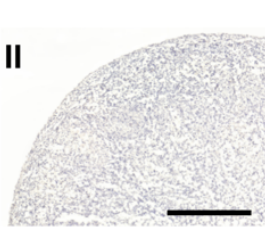

IV
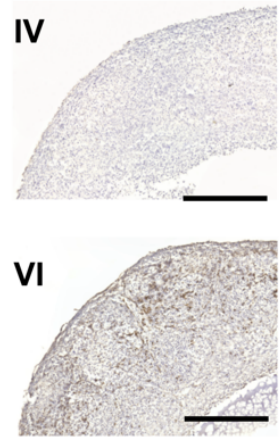

B

I

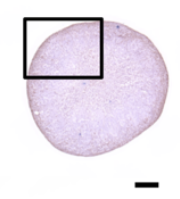

II

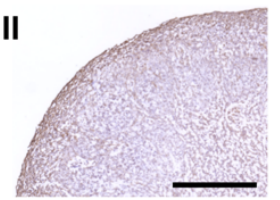

III

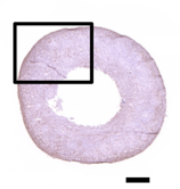

IV

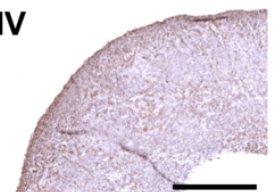

v

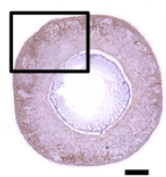

VI

D

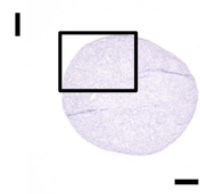

III

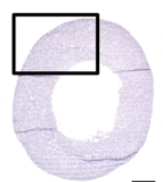

II

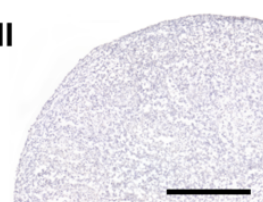

IV
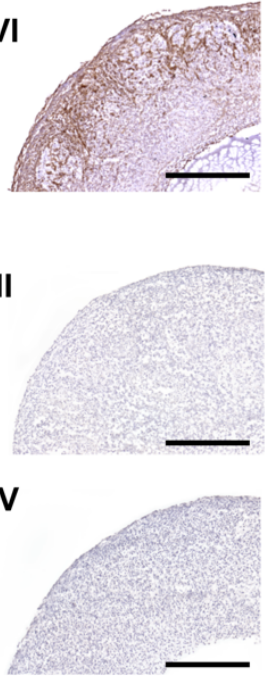

v

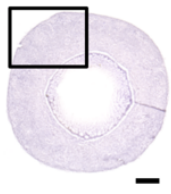

VI

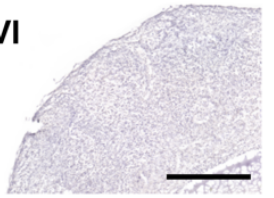

Figure 7. Imuuno-histochemical analysis for HGF, SDC1 and VEGF expression in WOC, TIC and HAC

Figure 7. Immunohistochemical analysis for HGF, SDC1, and VEGF expression in WOC, TIC, and HAC

(A-D) Images of immunohistochemical staining with anti-HGF (A), anti-SDC1 (B), anti-VEGF (C), and rabbit control IgG (D) antibodies in WOC (I, II), TIC (III, IV), and HAC (V, VI). II, IV, and VI are highly magnified views of the boxed areas in I, III, and $\mathrm{V}$, respectively. Brown indicates the presence of the target antigens. Nuclei were stained with hematoxylin. No positive staining was observed in tissues incubated with rabbit control IgG. Scale bars $=500 \mu \mathrm{m}$. WOC: 3D tubular structure without a core material; TIC: 3D tubular structure with a titanium core; HAC: 3D tubular structure with a hydroxyapatite core. 
A
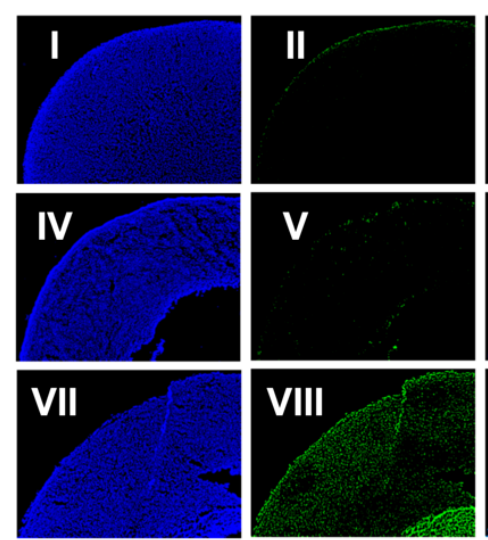

C
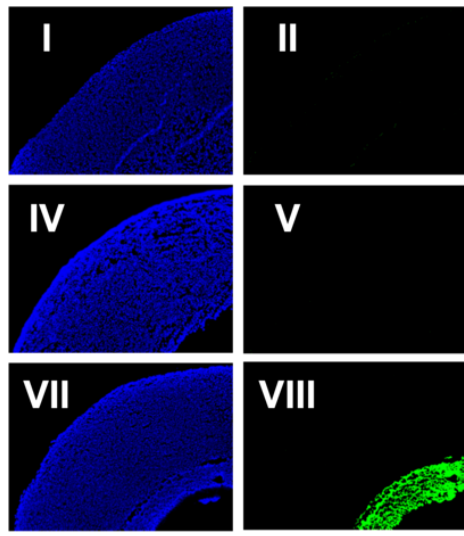
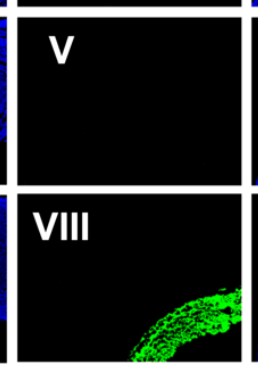

B
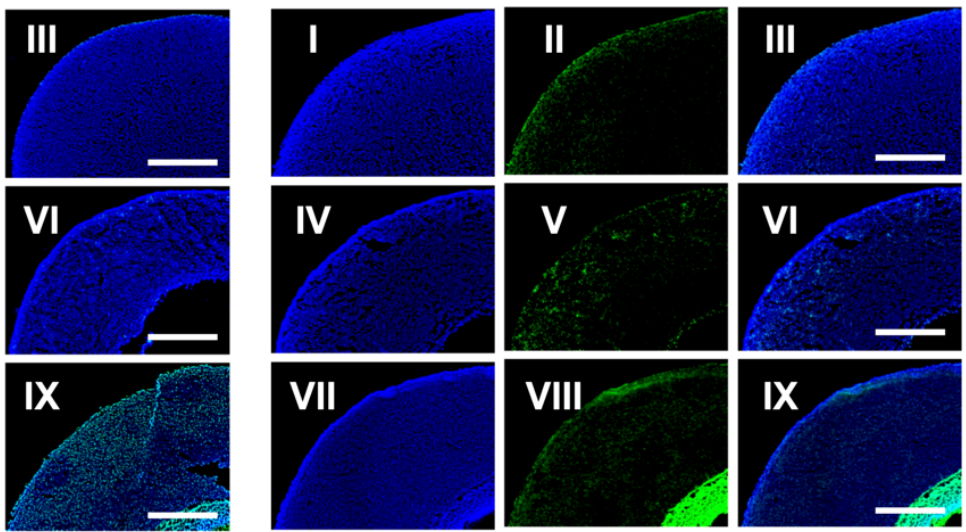

VIII
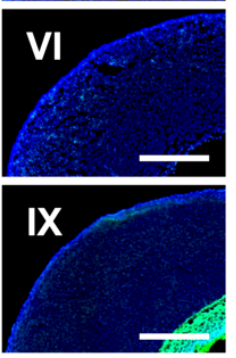

Figure 8. Immuno-fluorescent histochemical analysis for CEMP1 and OCN expression in WOC, TIC and HAC

Figure 8. Immunofluorescence histochemical analysis for CEMP1 and OCN expression in WOC, TIC, and HAC

(A-C) Images of immunofluorescence histochemical staining with anti-CEMP1 (A), anti-OCN (B), and rabbit control IgG (C) antibodies in WOC (I-III), TIC (IV-VI), and HAC (VII-IX). Green indicates the presence of the target antigens. Nuclei were stained with DAPI. No positive staining was observed in tissues incubated with rabbit control IgG. The strong green color in the middle of HAC indicates autofluorescence of the residual hydroxyapatite core. Scale bars $=500 \mu \mathrm{m}$. WOC: $3 \mathrm{D}$ tubular structure without a core material; TIC: 3D tubular structure with a titanium core; HAC: 3D tubular structure with a hydroxyapatite core. 

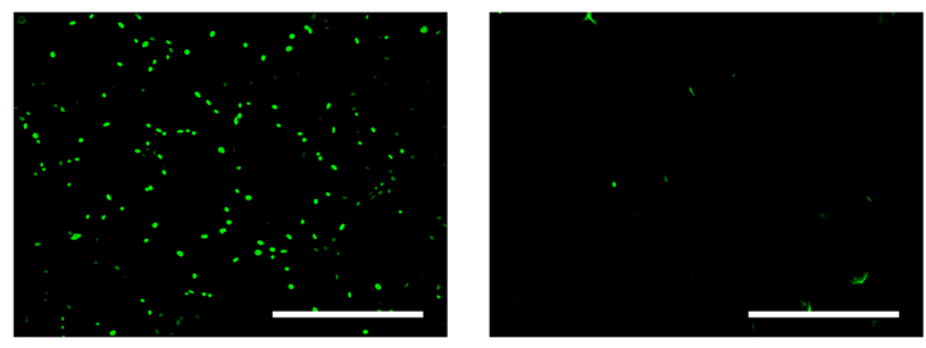

Figure S1. Cell viability analysis for monolayer-cultured line 1-17

Figure S1. Live cell distribution analysis in monolayer-cultured line 1-17 cells (A, B) Images of NucSpot staining in monolayer-cultured line 1-17 cells. The cells were treated with phosphate-buffered saline (PBS) (A) or 3\% $\mathrm{H}_{2} \mathrm{O}_{2}$ in PBS (B) for 10 min. Experiments were performed in duplicate. Representative images are shown. Green indicates NucSpot-positive living cells. Scale bars $=300 \mu \mathrm{m}$.
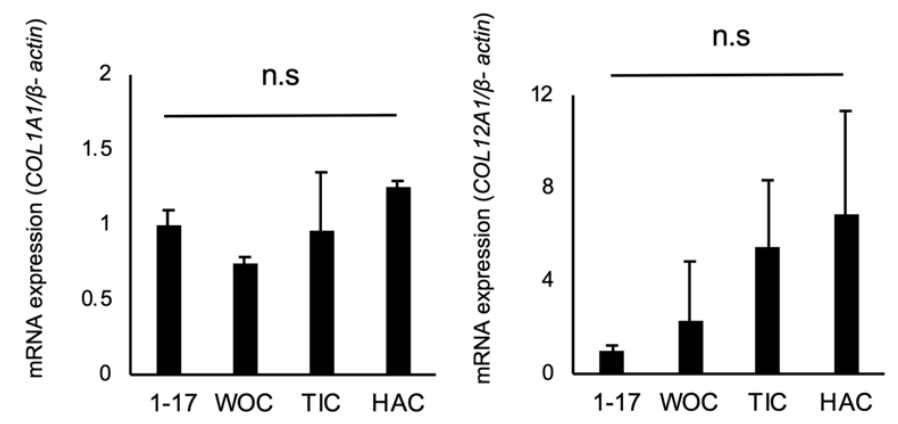

Figure S2. PDL-related collagen gene expression analysis for line 1-17, WOC, TIC and HAC

Figure S2. PDL-related collagen gene expression analysis in line 1-17 cells, WOC, TIC, and HAC

PDL-related collagen gene ( $C O L 1 A 1$ and $C O L 12 A 1)$ expression in monolayer-cultured line 1-17 cells, WOC, TIC, and HAC is shown. Gene expression levels were compared with real-time RT-PCR findings. Values are means \pm SD from three independent experiments. PDL: periodontal ligament; WOC: 3D tubular structure without a core material; TIC: 3D tubular structure with a titanium core; HAC: 3D tubular structure with a hydroxyapatite core. 
A
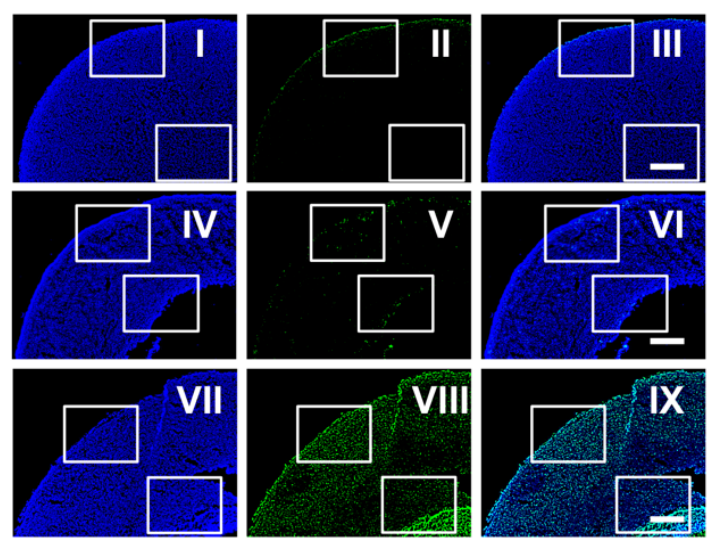

C
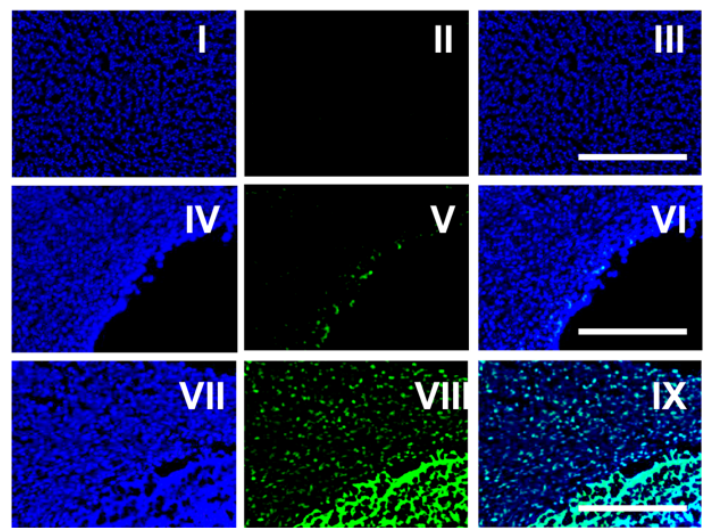

VII

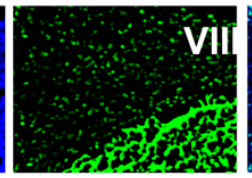

1
B

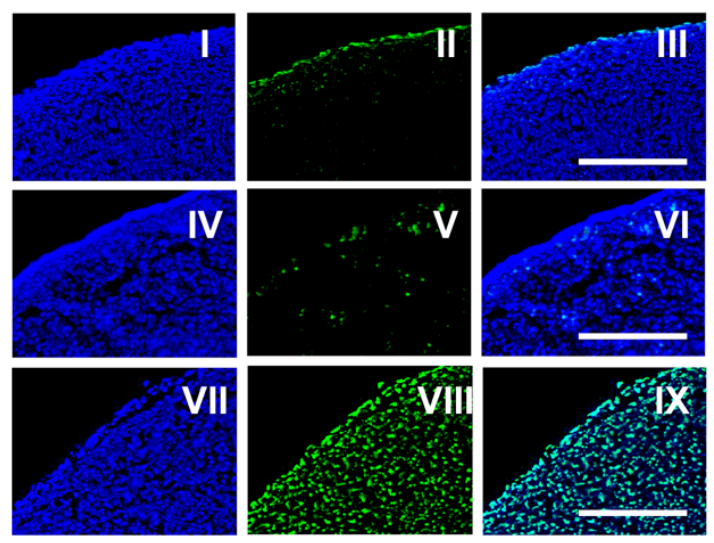

Figure S3. Highly magnified images of immunofluorescence histochemical analysis for CEMP1 expression in WOC, TIC, and HAC

Figure S3. Highly magnified images of immunofluorescence histochemical analysis for CEMP1 expression in WOC, TIC, and HAC

(A-C) Highly magnified images of Figure 8A. They are images of immunofluorescence histochemical staining with anti-CEMP1 in WOC (I-III), TIC (IV-VI), and HAC (VIIIX). The highly magnified images $(\mathrm{B}, \mathrm{C})$ correspond to the outermost area $(\mathrm{B})$ and middle lamella $(\mathrm{C})$ of the three-dimensional structure (A), respectively. Green indicates the presence of the target antigens. Nuclei were stained with DAPI. The strong green color in the middle of HAC indicates autofluorescence of the residual hydroxyapatite core. Scale bars $=250 \mu \mathrm{m}$. WOC: 3D tubular structure without a core material; TIC: $3 \mathrm{D}$ tubular structure with a titanium core; HAC: 3D tubular structure with a hydroxyapatite core. 
A
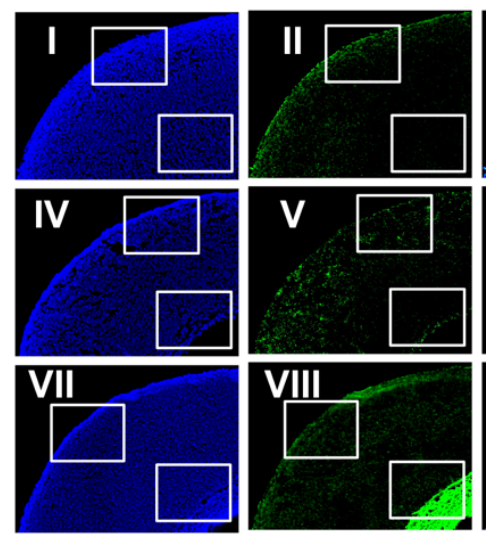

C

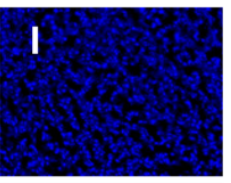

IV
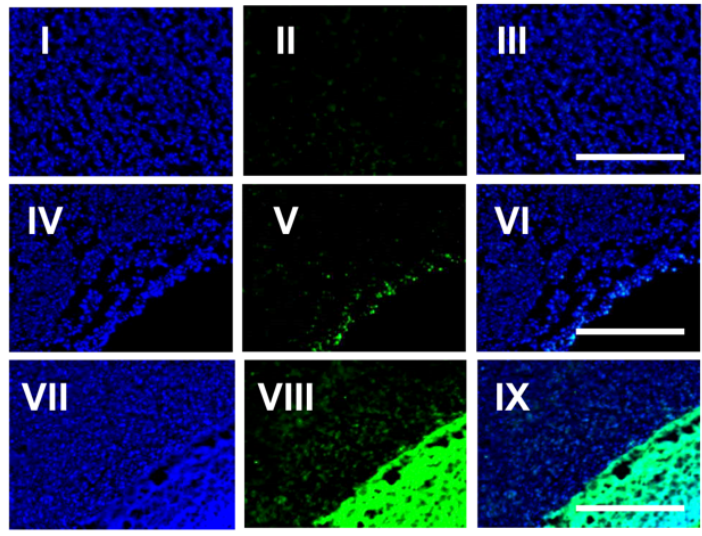

B
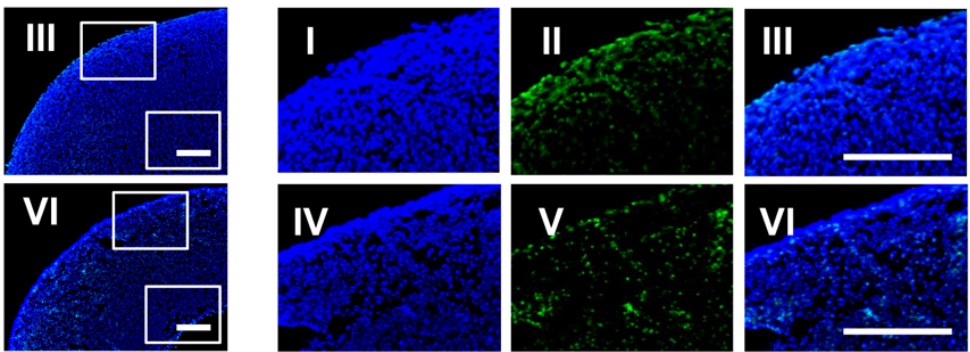

VII
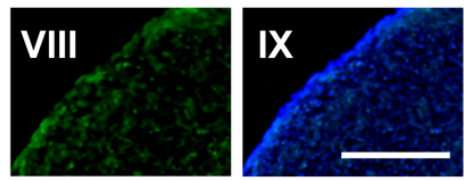

Figure S4. Highly magnified images of immunofluorescence histochemical analysis for OCN expression in WOC, TIC, and HAC

Figure S4. Highly magnified images of immunofluorescence histochemical analysis for OCN expression in WOC, TIC, and HAC

(A-C) Highly magnified images of Figure 8B. They are images of immunofluorescence histochemical staining with anti-OCN in WOC (I-III), TIC (IV-VI), and HAC (VIIIX). The highly magnified images $(\mathrm{B}, \mathrm{C})$ correspond to the outermost area $(\mathrm{B})$ and middle lamella (C) of the three-dimensional structure (A), respectively. Green indicates the presence of the target antigens. Nuclei were stained with DAPI. The strong green color in the middle of HAC indicates autofluorescence of the residual hydroxyapatite core. Scale bars $=250 \mu \mathrm{m}$. WOC: 3D tubular structure without a core material; TIC: 3D tubular structure with a titanium core; HAC: 3D tubular structure with a hydroxyapatite core. 
A
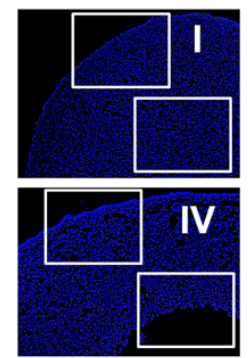

VII

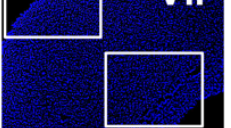

C
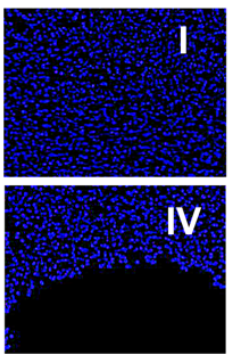

VII
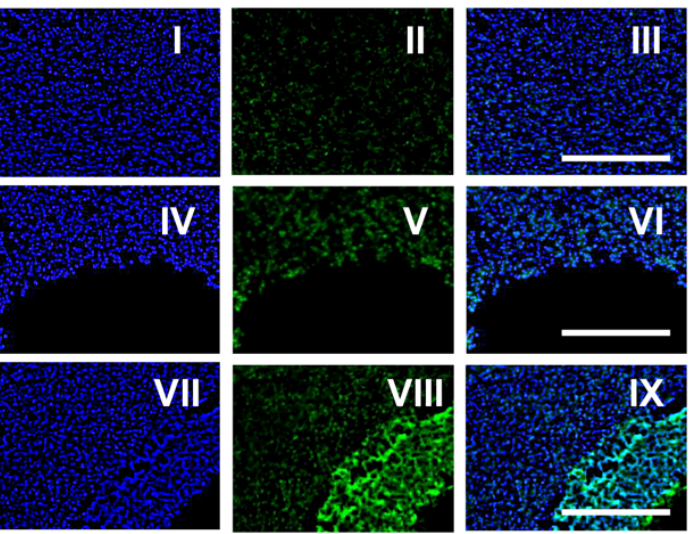

B
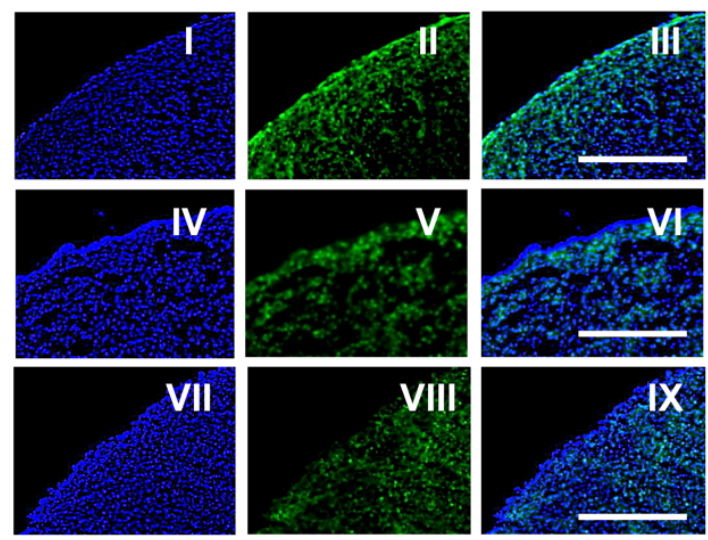

Figure S5. Immuno-fluorescent histochemical analysis for OSX expression in WOC, TIC and HAC

Figure S5. Immuno-fluorescent histochemical analysis for OSX expression in WOC, TIC and HAC

(A-C) Images of immunofluorescence histochemical staining with anti-OSX antibodies in WOC (I-III), TIC (IV-VI), and HAC (VII-IX). B and C are highly magnified views of the outer and inner boxed areas in A, respectively. Highly magnified images with Roman numerals correspond to each original image. Green indicates the presence of the target antigens. Nuclei were stained with DAPI. The strong green color in the middle of HAC indicates autofluorescence of the residual hydroxyapatite core. Scale bars $=250$ $\mu \mathrm{m}$. WOC: 3D tubular structure without a core material; TIC: 3D tubular structure with a titanium core; HAC: 3D tubular structure with a hydroxyapatite core. 
A
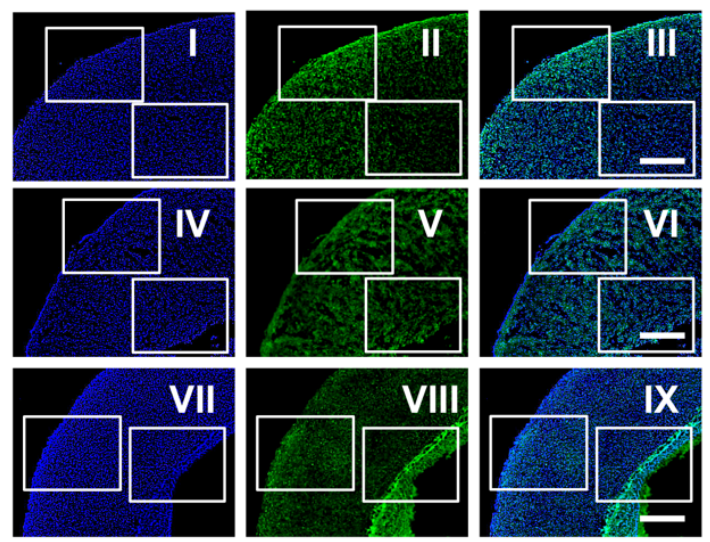

B
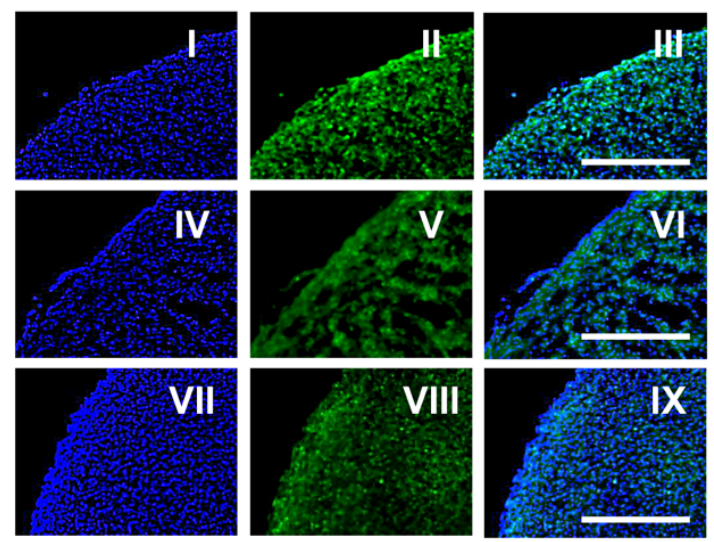

\section{C}
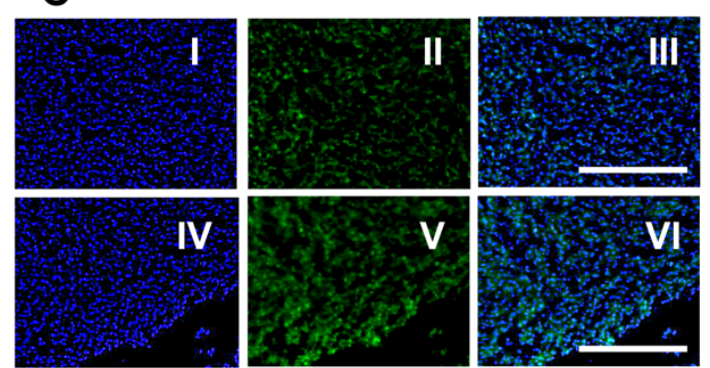

VII
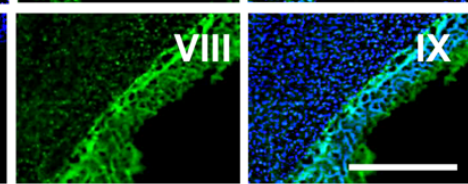

Figure S6. Immuno-fluorescent histochemical analysis for BMP2 expression in WOC, TIC and HAC

Figure S6. Immuno-fluorescent histochemical analysis for BMP2 expression in WOC, TIC and HAC

(A-C) Images of immunofluorescence histochemical staining with anti-BMP2 antibodies in WOC (I-III), TIC (IV-VI), and HAC (VII-IX). B and C are highly magnified views of the outer and inner boxed areas in A, respectively. Highly magnified images with Roman numerals correspond to each original image. Green indicates the presence of the target antigens. Nuclei were stained with DAPI. The strong green color in the middle of HAC indicates autofluorescence of the residual hydroxyapatite core. Scale bars $=250 \mu \mathrm{m}$. WOC: $3 \mathrm{D}$ tubular structure without a core material; TIC: $3 \mathrm{D}$ tubular structure with a titanium core; HAC: 3D tubular structure with a hydroxyapatite core. 